\title{
Scale-Up of Palladium Powder Production Process for Use in the Tritium Facility at Westinghouse, Savannah River, SC \\ Summary of FY99-FY01 Results for the Preparation of Palladium using the Sandia / LANL Process
}

\author{
David P. Baldwin, Daniel S. Zamzow, R. Dennis Vigil, and Jesse T. Pikturna \\ Ames Laboratory-USDOE, Iowa State University \\ Report IS-5149 \\ Ames, IA 50011 \\ August 24, 2001
}

\section{Introduction}

Palladium used at Savannah River (SR) for process tritium storage is currently obtained from a commercial source. In order to understand the processes involved in preparing this material, SR is supporting investigations into the chemical reactions used to synthesize this material. The material specifications are shown in Table 1. An improved understanding of the chemical processes should help to guarantee a continued reliable source of Pd in the future. As part of this evaluation, a work-for-others contract between Westinghouse Savannah River Company and Ames Laboratory (AL) was initiated. During FY98, the process for producing Pd powder developed in 1986 by Dan Grove of Mound Applied Technologies, USDOE (the Mound muddy water process) was studied to understand the processing conditions that lead to changes in morphology in the final product. ${ }^{1}$ During FY99 and FY00, the process for producing Pd powder that has been used previously at Sandia and Los Alamos National Laboratories (the Sandia/LANL process) was studied to understand the processing conditions that lead to changes in the morphology of the final Pd product. ${ }^{2,3}$ During FY01, scale-up of the process to batch sizes greater than 600 grams of Pd using a 20-gallon Pfaudler reactor was conducted by the Iowa State University (ISU) Chemical Engineering Department. This report summarizes the results of FY99-FY01 Pd processing work done at AL and ISU using the Sandia/LANL process.

In the Sandia/LANL process, Pd is dissolved in a mixture of nitric and hydrochloric acids. A number of chemical processing steps are performed to yield an intermediate species, diamminedichloropalladium $\left(\mathrm{Pd}\left(\mathrm{NH}_{3}\right)_{2} \mathrm{Cl}_{2}\right.$, or DADC-Pd), which is isolated. In the final step of the process, the $\mathrm{Pd}\left(\mathrm{NH}_{3}\right)_{2} \mathrm{Cl}_{2}$ intermediate is subsequently redissolved, and $\mathrm{Pd}$ is precipitated by the addition of a reducing agent (RA) mixture of formic acid and sodium formate. It is at this point that the morphology of the Pd product is determined. During FY99 and FY00, a study of how the characteristics of the Pd are affected by changes in processing conditions including the $\mathrm{RA} / \mathrm{Pd}$ molar ratio, $\mathrm{Pd}$ concentration, mole fraction of formic acid (mf-FA) in the RA solution, reaction temperature, and mixing was performed. These parameters all had significant effects on the resulting values of the tap density (TD), BET surface area (SA), and Microtrac particle size (PS) distribution for the Pd samples. These effects were statistically modeled and fit in order to determine ranges of predicted experimental conditions that resulted in material that meets the requirements for the Pd powder to be used at SR. Although not statistically modeled, the method and rate of addition of the RA and the method and duration of stirring were shown to be significant factors affecting the product morphology. Instead of producing an additional statistical fit and due to the likely changes anticipated during scale-up of this processing 
procedure, these latter conditions were incorporated into a reproducible practical method of synthesis. Palladium powder that met the SR specifications for TD, BET SA, and Microtrac PS was reliably produced at batch sizes ranging from 25-100 grams. In FY01, scale-up of the Sandia/LANL process was investigated by the ISU Chemical Engineering Department for the production of 600-gram batches of Pd. Palladium that meets the SR specifications for TD, BET SA, and Microtrac PS has been produced using the Pfaudler reactor, and additional processing batches will be done during the remainder of FY01 to investigate the range of conditions that can be used to produce Pd powder within specifications. Palladium product samples were analyzed at AL and SR to determine TD and at SR to determine BET SA, Microtrac PS distribution, and Pd nodule size and morphology by scanning electron microscopy (SEM).

\section{Experimental}

Detailed information regarding the procedures used for the preparation of the $\mathrm{Pd}\left(\mathrm{NH}_{3}\right)_{2} \mathrm{Cl}_{2}$ intermediate and for the Pd precipitation reaction are given in the FY99 and FY00 reports, which are attached to this report as Appendices $\mathrm{E}$ and $\mathrm{F}$. The laboratory equipment and components used in the AL bench-scale Pd processing experiments are listed in those reports; photographs of the some of the equipment used and some processing steps in the intermediate preparation and $\mathrm{Pd}$ precipitation procedures are also included in those reports. Reagent-grade chemicals and deionized (DI) water were used for the $\mathrm{Pd}\left(\mathrm{NH}_{3}\right)_{2} \mathrm{Cl}_{2}$ preparation and $\mathrm{Pd}$ precipitation reactions. Palladium sponge was obtained through the DOE Precious Metals Pool, Oak Ridge, TN.

Preparation of $\mathrm{Pd}\left(\mathrm{NH}_{3}\right)_{2} \mathrm{Cl}_{2}$ Intermediate: In the Sandia/LANL process, a number of chemical processing steps are performed that result in the formation of an intermediate species $\mathrm{Pd}\left(\mathrm{NH}_{3}\right)_{2} \mathrm{Cl}_{2}$ that is isolated and subsequently used in the Pd precipitation reaction. Palladium is dissolved in a mixture of nitric and hydrochloric acids. After dissolution, the Pd-acid mixture is heated and evaporated nearly to dryness. Hydrochloric acid $(\mathrm{HCl})$ is added to the residue to redissolve the Pd; this mixture is heated and evaporated nearly to dryness. Typically, two $\mathrm{HCl}$ addition and evaporation steps are performed to yield the acid-chloride species, $\mathrm{H}_{2} \mathrm{PdCl}_{4}$. The $\mathrm{H}_{2} \mathrm{PdCl}_{4}$ is dissolved in a sodium chloride solution, and this mixture is heated and evaporated nearly to dryness to form the sodium salt, $\mathrm{Na}_{2} \mathrm{PdCl}_{4}$. At least one DI water addition and evaporation step is performed to remove excess $\mathrm{HCl}$. The $\mathrm{Na}_{2} \mathrm{PdCl}_{4}$ is subsequently dissolved in DI water and heated to nearly boiling. Concentrated ammonium hydroxide $\left(\mathrm{NH}_{4} \mathrm{OH}\right)$ is added dropwise to the solution, with stirring, to form the tetraamminedichloropalladium species, $\mathrm{Pd}\left(\mathrm{NH}_{3}\right)_{4} \mathrm{Cl}_{2}$. The resulting solution is allowed to cool, filtered to remove impurities such as $\mathrm{Fe}(\mathrm{OH})_{3}$, and placed into an ice-bath. After cooling, cold $6 \mathrm{M} \mathrm{HCl}$ is added to the solution to precipitate $\mathrm{Pd}\left(\mathrm{NH}_{3}\right)_{2} \mathrm{Cl}_{2}$. The $\mathrm{Pd}\left(\mathrm{NH}_{3}\right)_{2} \mathrm{Cl}_{2}$ is recovered from solution by vacuum-filtration and allowed to air-dry for several days prior to being used in the Pd precipitation step. A more detailed description of the chemical processing steps involved in the preparation of the $\operatorname{Pd}\left(\mathrm{NH}_{3}\right)_{2} \mathrm{Cl}_{2}$ intermediate is given in Appendix 2 of AL Report IS-5137. ${ }^{2}$ A modified $\mathrm{Pd}\left(\mathrm{NH}_{3}\right)_{2} \mathrm{Cl}_{2}$ preparation procedure was used at ISU during FY01; a copy of this procedure is included as Appendix A.

Palladium Precipitation: The Pd precipitation reaction involves dissolving the $\mathrm{Pd}\left(\mathrm{NH}_{3}\right)_{2} \mathrm{Cl}_{2}$ intermediate in water and concentrated $\mathrm{NH}_{4} \mathrm{OH}$, heating the solution to the desired reaction temperature (typically $60^{\circ} \mathrm{C}$ ) in a stirred vessel, adjusting the $\mathrm{pH}$ to approximately 7.2 
by adding concentrated $\mathrm{HCl}$ dropwise (monitoring the $\mathrm{pH}$ using a $\mathrm{pH}$ electrode), and then adding an RA mixture of formic acid and sodium formate to precipitate the Pd powder. In order to make Pd powder that meets the SR specifications, an RA solution that is 4:1 RA/Pd molar ratio with a mf-FA ratio of approximately 0.25 , for an initial Pd solution concentration of 0.1 to 0.5 $\mathrm{M}$, is used. The RA is added to the stirred reaction vessel by pouring or pumping the RA solution into the dissolved Pd solution in approximately 10 seconds. The solution changes color from yellow to black, as $\mathrm{Pd}$ is reduced to the metal; the time for this color change is approximately 10 seconds, but varies somewhat depending on the reaction conditions used. After RA addition, the solution $\mathrm{pH}$ measured at 30 seconds is generally in the $\mathrm{pH} 5-6$ range. As the reaction proceeds, the $\mathrm{pH}$ increases, reaching a value of $\mathrm{pH} 8-9$ at the end of the 30-minute reaction time. After RA addition, the solution usually bubbles, as reaction gases (carbon dioxide and ammonia) evolve from solution. Depending on the reaction conditions used, the bubbling in solution can be very mild (or not observed) to very vigorous. As the reaction proceeds in the stirred vessel, the black-colored solution clears, as Pd nodules agglomerate into larger-sized clusters of particles that tend to settle out of solution at the bottom of the reactor. After the reaction is complete, the $\mathrm{Pd}$ is isolated by filtration, rinsed with DI water, dried in a drying oven, and sieved to 100-mesh. The dried, sieved Pd powder is subsequently analyzed to determine the TD, BET SA, Microtrac PS distribution, and nodule size and morphology by SEM.

The reaction conditions used for the individual $\mathrm{Pd}$ processing batches prepared at AL during the course of this work can be found in the prior year reports (Appendices $\mathrm{E}$ and $\mathrm{F}$ ), which list the batch size (mass of $\mathrm{Pd}$ precipitate); amounts of $\mathrm{Pd}\left(\mathrm{NH}_{3}\right)_{2} \mathrm{Cl}_{2}, \mathrm{NH}_{4} \mathrm{OH}$, formic acid, and sodium formate used; reducing agent to $\mathrm{Pd}$ molar ratio ( $\mathrm{RA} / \mathrm{Pd}$ ratio); mole fraction of formic acid (mf-FA) in the RA solution; initial Pd concentration (prior to RA solution addition); temperature; solution $\mathrm{pH}$; mixing method, time, and speed; and RA volume and addition rate. The TD, BET SA, and Microtrac PS distribution analysis results for the processing batches are tabulated in the attached reports. A description of the reaction conditions used for the batches, with some observations for the individual precipitation reactions, is also included in those reports. Reaction conditions and Pd powder analysis results for PD301-318 done at ISU in FY99 and FY00 are listed in Table II of this report; descriptions and observations for these individual batches are given in Appendix B. Reaction conditions and results for PD501-509 done in the Pfaudler reactor at ISU in FY01 are listed in Table III of this report; observations for these batches are given in Appendix D.

Palladium Precipitation using the Pfaudler Reactor: A 20-gallon glass-lined, clamp-top, stirred-tank reactor was purchased from Pfaudler Reactor Systems (model RT20-20-150-125) and used for the production of 600-gram-sized batches of Pd at ISU during FY01. The reactor vessel has an inside diameter of 20", an inside height of 18.75 " (from the bottom to the position of the gasket that separates the cover from the rest of the reactor), and a curved bottom. A steam jacket surrounds the bottom and the side walls of the reactor up to three-fourths of the reactor height. The reactor is fitted with a glass-lined, 4-blade pitched impeller designed for axial mixing; the bottom of the impeller blades is 6" above the bottom of the reactor. The impeller shaft is on-center with respect to the inside diameter of the reactor. The impeller is rotated by a $2 \mathrm{HP}, 60 \mathrm{~Hz}, 460 \mathrm{~V}$, frequency control, severe-duty motor. The motor drive is a model VMX150 single-reduction, 6:1 overall ratio, in-line gear reducer that is capable of producing impeller speeds of 50-300 rpm. The reactor is also equipped with a single $2 \frac{1}{2}$ "'-diameter glass-lined 
concave baffle that has an integral temperature sensor. Temperature control of the reactor is achieved using an Athean XT-32 electronic controller to control an on-off valve in the steam supply line.

The cover of the reactor has several fittings, including a 4 3/8"-diameter hand-hole with a double-pane, sight-glass hinged cover. Three inlet/outlet split-flange ports are located at 50, 125 , and $180^{\circ}$ angles from the position of the baffle. The $50^{\circ}$ port (a $2^{\prime \prime}$-diameter port) is connected to a flexible snorkel hood via a custom-made coupling and serves as the reactor exhaust line. The $125^{\circ}$ port is covered with a blank flange and is unused. The $180^{\circ}$ port (a 1 $1 / 2$ "-diameter port) serves as the RA addition port; it is covered with a flange that has a $\sim 1.25$ "diameter hole. A 26-mm I.D., 23"-long glass tube (with o-rings) is placed into this port when RA solution is added to the reactor during the Pd precipitation reaction. The position of the glass tube can be adjusted; for RA addition, the tube is set so that its bottom is at the same depth as the impeller blades.

The bottom outlet of the reactor is a 2"-diameter split-flange fitting that has a depth of 3" (which is the width of the steam jacket at the bottom of the reactor). The reactor outlet is fitted with a stainless steel ball valve that is connected to a strainer assembly (Rosedale model 8-125) that is fitted with a 150-mesh collection bag (McMaster-Carr part number 6805K11). Palladium and the reaction solution are pumped out of the reactor after a precipitation reaction is done using a diaphragm pump (ITT Jabsco model 31801-0115); Pd is collected in the 150-mesh bag, and the reaction solution is pumped to a 55-gallon polyethylene waste collection drum. The inlet and outlet ports for the steam supply are also located on the bottom of the reactor; the steam outlet port is fitted with a steam trap, and the condensate is collected in a small bucket. Photographs of the reactor and the filtration apparatus are shown in Figure 1, and design drawings for the reactor are shown in Figure 2. The procedures for performing Pd processing experiments using the Pfaudler reactor are given in Appendix C.

Palladium Powder Analysis: Samples are analyzed to determine the TD, SA, PS, and nodule size and morphology of the Pd powder formed in the precipitation reactions. Tap density analyses were performed at the AL Materials Preparation Center (MPC) and at SR. A portion of the Pd powder from the processing batches was sent to SR for BET SA and Microtrac PS distribution analyses, and SEM characterization of the Pd nodule size, uniformity, and morphology.

\section{Results \& Discussion}

Summary of Results for Pd Processing Batches:

The initial Pd processing batches that were prepared using the Sandia/LANL procedure at AL (PD201-210) were done using reaction conditions that were similar to those used previously at Sandia, in order to compare the results obtained at AL with the earlier work. For these batches, RA/Pd ratios ranging from approximately 2 to 12, initial Pd concentrations between approximately 0.1 and $0.5 \mathrm{M} \mathrm{Pd}$, and mf-FA ratios between 0 and 0.5 were used; the RA was added (poured) rapidly in approximately 2-3 seconds, and the Pd-RA solution was mixed briefly for 15 or 30 seconds. These conditions were used because they were believed to be similar to the procedure used at Sandia. The TD and SA values for PD201-210 weren't exactly the same 
as the values obtained at Sandia, but there was a reasonable correspondence in the values obtained (see Table 3 and Fig. 2 in FY99 report, Appendix E). Since none of these batches had TD and SA values that both met the SR specifications $\left(0.9-1.2 \mathrm{~g} / \mathrm{cc}\right.$ and $0.9-1.2 \mathrm{~m}^{2} / \mathrm{g}$, respectively), a number of additional batches (PD211-218 and 226-228) were done using varying reaction conditions to investigate the effects of changes in RA/Pd ratio, Pd concentration, mf-FA in the RA solution, and temperature on the Pd powder produced. Some of these met both of the TD and SA specifications; however, virtually all of these non-30-minute-mixed batches had Microtrac PS values that were too small, out of specification (see Table 2 in FY99 report, Appendix E). In addition, the SEM photomicrographs for these batches typically exhibited an undesirably high degree of dispersion in Pd nodule sizes, with some very small nodules and some relatively large nodules comprising the Pd powder samples produced using this method (see Fig. 3 in FY99 report, Appendix E).

The major difference in the processing conditions for the subsequent batches (PD219225, 229-255, and 401-414) compared to those discussed above was that the Pd-RA solution was mixed for the entire 30-minute reaction period after adding the RA to the Pd solution. These batches were made using RA/Pd ratios that varied between approximately 2 and 6, initial $\mathrm{Pd}$ concentrations between 0.1 and $0.5 \mathrm{M}$, and mf-FA ratios between 0.1 and 0.4 . Most of these batches were made using a reaction temperature of $60^{\circ} \mathrm{C}$ (some at $70^{\circ} \mathrm{C}$ and two at $40^{\circ} \mathrm{C}$ ). The RA addition method used also varied. For PD219-221, 224, and 232-234, the RA solution was added over a 1-minute period, generally adding most of the RA initially in approximately 10 seconds through a funnel, and adding the rest of the RA from 10 seconds to 1 minute using a tubing pump to deliver the RA to the funnel. For the rest of the batches in this group, all the RA was added initially in approximately 10 seconds, through a funnel placed into the Pd solution. The most obvious difference in the Pd powder analysis results for these batches, compared to PD201-218 and 226-228, was that the Microtrac PS values were larger, typically within the specified $\mathrm{d}_{25}, \mathrm{~d}_{50}$, and $\mathrm{d}_{75}$ ranges of 10-26, 21-47, and 30-67 $\mu \mathrm{m}$. Despite the relatively large differences in $\mathrm{RA} / \mathrm{Pd}$ ratios, $\mathrm{Pd}$ concentrations, mf-FA ratios, reaction temperature, and the manner in which the RA was added, all of these batches were mixed during the entire 30-minute reaction time. This resulted in an increase in the PS distribution of the Pd to a value that was generally within the SR specification. Also, the SEM photomicrographs for these 30-minutemixed batches typically showed Pd nodules that were more uniform in size, with much less dispersion in nodule sizes than those obtained for PD201-218 and 226-228 (see Fig. 9 in FY99 report, Appendix E, and Fig. 5 in FY00 report, Appendix F). This group of processing batches (most of PD219-414) forms the data set used for modeling the Pd processing conditions and the Pd powder analysis results, which is discussed in detail below.

From the results for PD219-414, it became evident that producing Pd powder having TD and SA values between 1-1.2 $\mathrm{g} / \mathrm{cc}$ and $1-1.2 \mathrm{~m}^{2} / \mathrm{g}$ simultaneously (the high end of the TD and SA specifications) was difficult to achieve, particularly for batches made at high Pd concentration. Although the chemical reaction conditions (RA/Pd ratio, Pd concentration, and mf-FA ratio) can be adjusted to increase either the TD or the SA, an inverse relationship between these two parameters generally applies. If the TD is increased, the SA decreases; if the SA is increased, the TD decreases. For PD415-421, the mixing speed used during the precipitation reaction was reduced, in an attempt to increase the TD of the Pd powder while maintaining a high SA. The results for these batches show that the TD increases, the Microtrac PS distribution decreases, and 
the SA is essentially unaffected by the reduction in mixing speed (see Fig. 4 and Fig. 1 in FY00 report, Appendix F). These results are consistent with the hypothesis that the SA of the Pd powder is determined primarily by the chemical conditions in the early stages of the precipitation reaction (nucleation and growth of Pd nodules), while the TD and PS are influenced by the mixing conditions (agglomeration and collision of nodules to form clusters of particles) as the reaction proceeds. This premise is discussed in more detail below.

Batches PD422-425 and 602-604 were done using a round-bottomed glass reactor that was a scaled-down version of the 20-gallon Pfaudler reactor used by the ISU Chemical Engineering Department for the production of kilogram-sized batches of Pd. The glass reactor is dimensionally about 2.9 times smaller (24.4 times smaller volume) than the Pfaudler reactor, allowing production of 25-110 gram batches of Pd. A PVC baffle and a 4-blade PVC mixer paddle were used, with a centered mixing configuration, for these batches. Palladium powder that met the SR specifications for TD, BET SA, and Microtrac PS distribution was produced using this scaled-down reactor (see Table 2 in FY00 report, Appendix F). Thus, the changes in reactor geometry (round-bottomed reactor compared to glass beakers used for PD219-421), mixer impeller (4-blade compared to dual-blade impeller), and mixing configuration (centered mixing with baffle compared to off-center mixing for most of PD219-421) did not significantly affect the characteristics of the Pd powder produced.

For PD602-604, the solution $\mathrm{pH}$ was monitored throughout the precipitation reaction. The $\mathrm{pH}$ data for $\mathrm{PD} 602$ is displayed in Figure 3. The $\mathrm{pH}$ decreased from the initial $\mathrm{pH} \sim 7.2$ value to $\mathrm{pH} 4.5$ as the RA solution was added and mixed. For PD602, the $\mathrm{pH}$ increased slowly until about two minutes into the reaction. At this point, bubbling-in-solution started and continued for less than a minute; the $\mathrm{pH}$ measured during this period increased rapidly from about $\mathrm{pH} 5$ to $\mathrm{pH}$ 8. Throughout the remaining 27 minutes of the precipitation reaction, relatively little change in $\mathrm{pH}$ occurred, with a final $\mathrm{pH}$ of 8.4 measured for PD602. For PD603 and 604, a similar pattern in the measured $\mathrm{pH}$ was obtained; the solution $\mathrm{pH}$ decreased rapidly during $\mathrm{RA}$ addition and mixing, and increased rapidly during the bubbling-in-solution stage of the reaction. Batches PD603 and 604 were prepared using a higher reaction temperature $\left(79^{\circ} \mathrm{C}\right.$, with $4: 1 \mathrm{RA} / \mathrm{Pd}$ ratio, $0.1 \mathrm{M}$ initial $\mathrm{Pd}$ concentration, and $0.25 \mathrm{mf}-\mathrm{FA}$ ratio for $\mathrm{PD} 603 ; 75^{\circ} \mathrm{C}$, with $4: 1 \mathrm{RA} / \mathrm{Pd}$ ratio, 0.5 $\mathrm{M}$ initial $\mathrm{Pd}$ concentration, and $0.23 \mathrm{mf}-\mathrm{FA}$ ratio for PD604). These batches were done to investigate whether the use of a higher reaction temperature would result in the production of $\mathrm{Pd}$ powder having both high TD and high SA. For PD415-421, high TD and high SA (and small PS) Pd was produced by reducing the mixing speed during the precipitation reaction, thereby reducing the collision frequency of Pd particles during the agglomeration period of the precipitation reaction. By increasing the reaction temperature, the hypothesis is that the reaction will proceed faster thereby allowing less time for collisions between Pd clusters to occur during the agglomeration period, resulting in Pd that is comprised of smaller, less ramified particles that pack more easily into a higher TD powder. For PD603 and 604, high TD (1.34 and $1.29 \mathrm{~g} / \mathrm{cc}$, respectively) and high SA (1.9 and $\left.1.5 \mathrm{~m}^{2} / \mathrm{g}\right)$ Pd powders were, in fact, produced. The TD and SA values are both out of specification (too high) and the $\mathrm{d}_{50}$ Microtrac PS values (5.6 and 18.6 $\mu \mathrm{m})$ are too small, indicating that a reaction temperature of $75-80^{\circ} \mathrm{C}$ is too high for these processing conditions to make $\mathrm{Pd}$ that meets the SR specifications. It is also important to note that for PD604, done at $75^{\circ} \mathrm{C}$ and $0.5 \mathrm{M}$ initial $\mathrm{Pd}$ concentration, excessive bubbling-in-solution 
occurred during the reaction, resulting in $\mathrm{Pd}$ and solution foaming over the top of the glass reactor into the water-recirculating bath.

PD601 was a set of preliminary stopped-flow reactions, for which the Pd and RA solutions were pumped through a mixing tube to initiate the $\mathrm{Pd}$ precipitation reaction that was subsequently quenched at differing times by adding cold hydrogen peroxide $\left(\mathrm{H}_{2} \mathrm{O}_{2}\right.$ at $\left.0^{\circ} \mathrm{C}\right)$ to the flowing Pd-RA solution mixture. Differing lengths of tygon tubing were attached to the mixer tube (in a $60^{\circ} \mathrm{C}$ water-recirculating bath) to provide reaction times of $15,30,60$, and 120 seconds. For these reactions, the initial Pd solution concentration was $0.5 \mathrm{M}$, and the RA was a solution of $4: 1 \mathrm{RA} / \mathrm{Pd}$ ratio and $0.23 \mathrm{mf}-\mathrm{FA}$ ratio. The $\mathrm{Pd}$ isolated from the collected Pd-RA$\mathrm{H}_{2} \mathrm{O}_{2}$ solutions was analyzed by SEM to determine the characteristics of the Pd powder formed in the 15- to 120-second time period of the precipitation reaction. For the 15-second reaction time, there are some small clusters of $\mathrm{Pd}$ that are about $1 \mu \mathrm{m}$ in size (some smaller than $1 \mu \mathrm{m}$, some larger), as shown in Figure 4a. By one minute into the reaction, there is evidence of larger clusters of $\mathrm{Pd}$, with some greater than $10 \mu \mathrm{m}$ in size (see Figure $4 \mathrm{~b}$ ). Thus, based on these preliminary experiments, it appears that agglomeration of Pd nodules into relatively large-sized clusters is occurring relatively early in the Pd precipitation reaction. For these processing conditions in a batch reactor, the bubbling-in-solution stage of the reaction would be expected to start about 50 seconds after adding the RA to the Pd solution. Because of the differences in reactor and mixing geometries, it is unclear whether the results for these stopped-flow reactions are directly applicable to the stirred-batch Pd processing experiments. In particular, the relative mixing energy in the flow experiment may be higher, leading to earlier agglomeration of smaller nodules.

Palladium processing batches PD301-318 (see Table II and Appendix B) were done in the ISU Chemical Engineering Department in order to reproduce some of the AL work and to gain experience in preparing Pd powder on a small scale, 20-110 gram batch sizes. Some of these batches were nominal duplicates of AL batches, however, several experiments were also performed in order to explore the effects of using various impeller configurations, mixing speed conditions, and reactant concentrations. The average TD for these 18 batches was $1.05 \mathrm{~g} / \mathrm{cc}$ (with a range of $0.53-1.53 \mathrm{~g} / \mathrm{cc}$ ), the average SA was $0.86 \mathrm{~m}^{2} / \mathrm{g}(0.52-2.2 \mathrm{~m} / \mathrm{g}$ ), and the average $\mathrm{d}_{50}$ PS value was $36.5 \mu \mathrm{m}(15.8-63.4 \mu \mathrm{m})$. Five of these 18 (PD302, 303, 311, 314, and 317) met the SR specifications for TD, BET SA, and Microtrac PS distribution. A sixth (PD313) also met the specifications, if the SA is rounded to the nearest tenth of the unit of measurement $\left(0.9 \mathrm{~m}^{2} / \mathrm{g}\right)$. For PD301-318, some of the initial and some of the later batches met the SR specifications, but a number of the intervening batches (PD304-310) did not. For PD304310 , some of the TD values are in specification, the BET SA is too low (except for PD310, which is too high), and the Microtrac PS distribution is generally in specification (although some of the values are too high and those for PD310 are too low - see Table II). The initial solution $\mathrm{pH}$ for these batches was not adjusted to a value of $\mathrm{pH} 7.2-7.3$ prior to RA addition. The variation in initial $\mathrm{pH}$ (with values ranging from $\mathrm{pH} 6.9$ - 7.5 for PD304-310) undoubtedly affected the results; however, there are other experimental factors that also contributed to the results for individual batches not meeting all of the SR specifications. For instance, for PD304 the mixer stopped during the precipitation reaction (high torque shut-down) so the solution was not stirred the entire time; PD308 was purposely done using a glass beaker that had not been cleaned after doing the prior batch to see the effect of using a "dirty" reactor. For PD310, all the 
RA solution was added in less than one second, resulting in the production of $\mathrm{Pd}$ powder having very low TD $(0.53 \mathrm{~g} / \mathrm{cc})$, very high SA $\left(2.2 \mathrm{~m}^{2} / \mathrm{g}\right)$, and small Microtrac PS $\left(\mathrm{d}_{50}\right.$ value of 15.8 $\mu \mathrm{m})$. For PD311-318, more careful attention to the following the specific details of the precipitation reaction procedures, including more precisely adjusting the initial solution to a value of $\mathrm{pH}$ 7.2-7.3 prior to RA addition, was done. This is part of the reason why the results for these batches are more consistently within the SR specifications. Some preliminary scale-up criteria were also investigated in the course of doing PD301-318, which is discussed below.

Batches PD501-509 were done using the 20-gallon Pfaudler reactor in the ISU Chemical Engineering Department, using the procedures in Appendix C. The reaction conditions and Pd powder analysis results for these batches are listed in Table III, and observations for the individual batches are given in Appendix D. The results for PD501-509 are discussed in detail below.

\section{Modeling of Reaction Conditions and Pd Powder Characteristics:}

Batches PD219-414 (most of these batches) form the data set used for modeling the Pd processing conditions and the Pd powder analysis results. Multiple linear regression analyses of the TD, SA, and PS values were performed using Microcal Origin version 6.0 software (Microcal Software, Inc.), fitting the RA/Pd ratio, Pd concentration, mf-FA ratio, temperature, and batch size, plus a constant term, for each of the three Pd powder characteristics. Linear and quadratic terms for each of the five experimental reaction conditions were considered, eliminating some of the terms based on iterative tests of the significance of these variables to the overall quality of the fit. A number of different models were generated, using the results for PD219-255 (done in FY99) and those for PD401-414 (done in FY00). The fit parameters, with their associated errors, for the modeled TD, SA, and $\mathrm{d}_{50}$ PS for a number of these models are given in Table 3 of the FY00 report, Appendix F. For the PD219-412 model, the best fit for TD was obtained using linear and quadratic terms in $\mathrm{RA} / \mathrm{Pd}$ ratio, $\mathrm{Pd}$ concentration, and mf-FA ratio. For $\mathrm{SA}$, linear terms in $\mathrm{RA} / \mathrm{Pd}$ ratio, $\mathrm{Pd}$ concentration, and mf-FA ratio were used, along with quadratic terms for RA/Pd ratio and temperature. The $\mathrm{d}_{50} \mathrm{PS}$ was modeled using linear terms in $\mathrm{RA} / \mathrm{Pd}$ ratio, $\mathrm{Pd}$ concentration, and mf-FA ratio, plus a quadratic term for $\mathrm{RA} / \mathrm{Pd}$ ratio. There is reasonably good agreement between the measured and fitted values for most of the batches (see Fig. 1 in FY00 report, Appendix F). For TD, most of the fitted values are within $+/-0.07 \mathrm{~g} / \mathrm{cc}$ of the measured values (root-MSE for the PD219-412 model is $0.066 \mathrm{~g} / \mathrm{cc}$ ). For some batches, however, the difference between the fitted and measured values is larger, with the maximum errors being (-) $0.126 \mathrm{~g} / \mathrm{cc}$ for PD249 and $0.121 \mathrm{~g} / \mathrm{cc}$ for PD412. The PD219-412 fit of SA is poorer than that for TD. Most of the fitted SA values are within $+/-0.12 \mathrm{~m}^{2} / \mathrm{g}$ of the measured values (root-MSE of $0.12 \mathrm{~m}^{2} / \mathrm{g}$ ), but the errors are larger for some batches (maximum errors of $0.276 \mathrm{~m}^{2} / \mathrm{g}$ for PD223 and $0.178 \mathrm{~m}^{2} / \mathrm{g}$ for PD412). For $\mathrm{d}_{50} \mathrm{PS}$, the PD219-412 fitted values are generally within $+/-7 \mu \mathrm{m}$ of the measured values (root-MSE of $6.3 \mu \mathrm{m}$ ). The maximum errors are $-15.7 \mu \mathrm{m}$ for PD246 and 12.6 $\mu \mathrm{m}$ for PD223. Thus, the PD219-412 model can be used to predict the TD for a given set of reaction conditions to less than $0.1 \mathrm{~g} / \mathrm{cc}$, the SA to a value slightly greater than $0.1 \mathrm{~m}^{2} / \mathrm{g}$, and the $\mathrm{d}_{50}$ PS to within about $7 \mu \mathrm{m}$. This is valid for most sets of reaction conditions that are within the ranges of the PD219-412 model.

Three-dimensional plots of the PD219-412 modeled TD, SA, and $\mathrm{d}_{50}$ PS are shown in Figure 2 of the FY00 report, Appendix F. These plots show the combination of processing 
conditions that, based on the PD219-412 model, should yield Pd powders that meet the SR specifications of 0.9-1.2 g/cc TD, 0.9-1.2 $\mathrm{m}^{2} / \mathrm{g} \mathrm{SA}$, and 21-47 $\mu \mathrm{m} \mathrm{d}_{50}$ PS values. Correlation plots of TD, SA, and $\mathrm{d}_{50}$ PS obtained for processing batches PD219-425, combining the FY99 (PD219-255) and FY00 (PD401-425) results are shown in Figure 3 of the FY00 report, Appendix F. These figures show the trends in TD, BET SA, and Microtrac PS for the Sandia/LANL process. Tap density and SA are inversely related - Pd powder having a high TD generally has a low SA and vice-versa (see Fig. 2a-d and Fig. 3a). Surface area and $\mathrm{d}_{50} \mathrm{PS}$ are strongly inversely correlated for all of the batches made in FY99 and FY00. High SA Pd is produced when the Microtrac PS distribution is small; if the PS distribution is large, the SA is low (Fig. 3b). There is no obvious trend or correlation between TD and $\mathrm{d}_{50}$ PS for batches PD219-425 (Fig. 3c). Based on the PD219-412 model, the following statements can be made regarding the expected changes in Pd powder characteristics for changes in processing conditions. If the $\mathrm{RA} / \mathrm{Pd}$ ratio decreases (from an $\mathrm{RA} / \mathrm{Pd}$ ratio of 4:1), then for a given set of $\mathrm{Pd}$ concentration and mf-FA reaction conditions within the ranges of the PD219-412 model, the TD increases, the SA decreases, and the PS increases. Increasing the RA/Pd ratio has the opposite effect. For a given set of RA/Pd and mf-FA conditions, increasing the Pd concentration results in a slight decrease in TD, a slight increase in SA, and a slight increase in PS. An increase in the mf-FA ratio (for a given set of $\mathrm{RA} / \mathrm{Pd}$ and $\mathrm{Pd}$ concentration conditions) results in a decrease in $\mathrm{TD}$, an increase in SA, and a decrease in PS. The predicted TD, SA, and $\mathrm{d}_{50}$ PS values for a given set of RA/Pd, Pd concentration, and mf-FA processing conditions can be calculated for a given model using the fit parameters listed in Table 3 of the FY00 report (Appendix F). It should be noted that the results for the mixing-speed-reduction batches, PD415-425 and 602604, are not included in any of the models in Appendix F. Based on the results for PD603 and 604 (done at 79 and $75^{\circ} \mathrm{C}$ ), it is likely that the models under-represent the temperature dependence on the TD, SA, and PS of the Pd powder. As a result, predicted TD, SA, and PS values for reaction conditions using a temperature other than $60^{\circ} \mathrm{C}$ are likely to have larger errors than the root-MSE values listed above.

\section{Palladium Processing using the Sandia/LANL Process:}

It is our current understanding that the selection of $\mathrm{pH}$, temperature, and relative concentration of reactants (Pd, RA, and formic acid/sodium formate ratio) controls the SA for the Pd powder. This may be explained by the hypothesis that, under reasonable initial mixing conditions, the solution begins as saturated in reactants to a point where the Pd nodules are nucleated. All of the nodules are born at this initial stage (in very short period of time) and the solution drops below the critical conditions where new nodules may be formed. Under continued effective mixing, all of the nodules will grow at the same rate and will be uniform throughout the medium. Given the right initial conditions, this will lead to the proper nodule size $\left(\sim 0.5-\mu \mathrm{m}\right.$ diameter) that will result in a SA of about $1 \mathrm{~m}^{2} / \mathrm{g}$. We have studied a range of $\mathrm{pH}$ and relative concentration conditions that allow us to produce powders that meet specifications at $60^{\circ} \mathrm{C}$ from 0.1 to $0.5 \mathrm{M}$ initial $\mathrm{Pd}$ concentration.

However, the range of conditions used results in Pd powder with TD and SA values consistently toward the lower end of the specified ranges, especially for high Pd concentration batches. (For low Pd concentration batches, the values are more toward the middle to high end of the TD and SA ranges.) It is desirable to bring these properties to the high end of their ranges simultaneously. It does not appear that this is possible only by varying the chemical parameters 
that we have investigated over most of the term of this project. Given the above hypothesis, the $\mathrm{SA}$ is fixed by the initial conditions. The TD and cluster-size distribution (Microtrac PS) are determined during the subsequent several minutes of the reaction. The second hypothesis is that after the initial creation of nodules, they continue to grow until all of the Pd is removed from the solution, under conditions of excess RA. During this growth period, the particles collide with one another and stick, forming clusters of these growing nodules. It is the collision rate and the length of time until depletion of Pd that determines the size of the clusters. Therefore the TD and PS are determined during this second stage of the reaction. For PD415-425, the initial conditions were selected to produce a SA at the high end of its specification. For these batches, the mixing speed was lowered following the initial addition of reactants, and the effects on TD and PS were observed. As one would expect given our hypotheses, the reduction in stirring rate resulted in decreased PS distribution and increased TD, without affecting the SA (as compared to batches prepared using constant higher stirring rates). This set of conditions allowed us to produce powders with both TD and SA values closer to the high end of the specified ranges. The results for PD603-604 indicate that using a reaction temperature greater than $60^{\circ} \mathrm{C}$ will also enable production of $\mathrm{Pd}$ with high $\mathrm{TD}$ and high $\mathrm{SA}$. There may be a reaction temperature region (somewhere between 60 and $75^{\circ} \mathrm{C}$ ) that will allow the production of high TD and high SA Pd powder that meets the SR specifications.

Scale-up Considerations for the Sandia/LANL Palladium Process:

The complex interplay between fluid dynamics, heat transfer, phase behavior, and chemical reaction make it nearly impossible to scale up reactive precipitation processes from first-principles calculations. Indeed, it can be difficult to accurately simulate even one singlephase reaction undergoing turbulent flow in a stirred reactor due to difficulties associated with turbulence closure schemes and the need for a sliding mesh/moving boundaries. Furthermore, the large number of parameters that must be independently determined for a meaningful firstprinciples calculation of reactive precipitation in a stirred-tank reactor is prohibitive, even when the chemistry is understood. In the present case, very little is understood concerning the precise mechanism by which the Pd particles are formed, and there are likely numerous chemical reactions that occur during the process which have not yet been identified. In view of these considerations, any useful scale-up criteria for reductive precipitation of Pd metal will likely emerge as a result of an empirical program informed by insights into key mechanistic steps of the process.

In the absence of information needed for reliable first-principles simulations of non-ideal chemical reactors, several simple, but often useful, scale-up rules can be applied. Among these are the commonly employed "constant tip speed" and "constant power/volume" scale-up criteria. The former scale-up rule makes use of the assumption that most micromixing (and reaction) occurs near the impeller tips, where the fluid flow is highly turbulent and where much of the energy dissipation occurs. In this scenario, the use of a constant impeller tip speed ensures dynamic similarity. If the reactor volume is relatively small so that the power imparted to the fluid by the impeller is dissipated relatively evenly throughout the reactor, then constant power/volume scale-up criteria may apply.

In the first phase of the ISU portion of this work, experiments PD301-318, an effort was made to investigate both the constant tip speed and constant power/volume scale-up criteria. 
This effort, however, was complicated by the use of different chemistries (e.g. Pd concentration, $\mathrm{RA} / \mathrm{Pd}$ molar ratio, and mf-FA ratio), impellers (number and type of blades), and reactor geometries (e.g. impeller-to-reactor diameter ratios). Nevertheless, the constant power/volume scale-up criteria appeared to be moderately useful for predicting scale-up conditions.

Furthermore, some theoretical basis exists for preferring the constant power/volume rule, as is explained below.

Experiments at the bench scale (batch size $<100$ grams) showed quite clearly that vigorous mixing of the reactor after addition of the RA led to lower TD. Surface area, on the other hand, was relatively insensitive to mixing considerations but rather depended strongly on the chemical conditions. Our interpretation of this result is as follows. The Pd primary particles (spherical nodules) are formed very rapidly after the RA is introduced into the reactor and the solids SA is fixed. Once these primary particles are formed, they undergo aggregation to form the final larger clusters. It is well known that the rate of aggregation of a solid particulate phase in a turbulent flow field is directly proportional to the turbulent energy dissipation rate, which in turn is directly proportional to the power/volume input by the impeller. However, upon scale-up of the reactor, one can expect that the turbulent energy dissipation will become increasingly nonhomogeneous, thereby leading to a greater polydispersity in the cluster-size distribution. Furthermore, the local supersaturation and strain rate will also become spatially nonhomogeneous, thereby leading to different rates of nucleation and therefore a larger distribution in the sizes of the primary spheres. Nevertheless, because of the crucial role that aggregation plays in determining the TD of the resulting Pd powder, we chose to focus on the constant power/volume scale-up criterion for experiments conducted in the Pfaudler reactor. The experimental conditions for these constant power/volume scale-up experiments were obtained from results of a series of experiments carried out on a smaller, but geometrically similar, reactor constructed by AL (PD422-425 and PD602-604). Note that for geometrically-similar reactors filled with the same fluid,

$$
\frac{P}{V}=K D^{2} \omega^{3}
$$

where $P$ is power, $V$ is the reactor fluid volume, $D$ is the impeller diameter, and $\omega$ is the angular velocity of the impeller. The constant of proportionality, $K$, is invariant upon scale-up as long as geometric similarity is maintained and the fluid properties are identical.

\section{Pfaudler Reactor Experiments:}

The processing conditions and analytical results for the nine experiments carried out in the Pfaudler reactor are listed in Table III, and the experimental notes are given in Appendix D. The mixing speeds, RA addition times, and Pd powder analysis results for PD501-509 are summarized in Table IV. Note that in all experiments the impeller speed, if it was varied, was changed 3 minutes after adding the RA. Also, all experiments listed in Table IV were run using the same nominal chemical conditions including the initial $\mathrm{Pd}\left(\mathrm{NH}_{3}\right)_{2} \mathrm{Cl}_{2}$ concentration $(0.1 \mathrm{M})$, $\mathrm{RA} / \mathrm{Pd}$ ratio (4:1), and mf-FA ratio (0.254).

\footnotetext{
Table IV. Pfaudler Reactor Results
} 


\begin{tabular}{|c|c|c|c|c|c|c|c|c|}
\hline Run & $\begin{array}{c}\text { Impeller } \\
\text { Speed } \\
\text { Early/Late } \\
(\mathrm{rpm})\end{array}$ & $\begin{array}{c}\text { RA } \\
\text { Addition } \\
\text { Time } \\
(\text { seconds })\end{array}$ & $\begin{array}{c}\text { Pd } \\
\text { Batch } \\
\text { Size } \\
(\mathrm{grams})\end{array}$ & $\begin{array}{c}\text { Tap } \\
\text { Density } \\
\left(\mathrm{g} / \mathrm{cm}^{3}\right)\end{array}$ & $\begin{array}{c}\text { Surface } \\
\text { Area } \\
\left(\mathrm{m}^{2} / \mathrm{g}\right)\end{array}$ & \multicolumn{4}{|c|}{$\begin{array}{c}\text { Microtrac } \\
\text { Particle Size } \\
(\mu \mathrm{m})\end{array}$} \\
\hline PD501 & $130 / 70$ & 12 & 577 & 1.7 & 1.2 & 4.1 & 6.9 & 11 \\
\hline PD502 & $130 / 190$ & 12 & 631 & 1.4 & 1.1 & 6.1 & 11.4 & 18.1 \\
\hline PD503 & $130 / 262$ & 12 & 632 & 1.5 & 1.0 & 8.5 & 15.3 & 24.3 \\
\hline PD504 & $262 / 262$ & 11 & 623 & 1.4 & 1.0 & 7.8 & 13.9 & 21.8 \\
\hline PD505 & $130 / 130$ & 11 & 623 & 1.6 & 1.2 & 6.6 & 13.7 & 24.9 \\
\hline PD506 & $130 / 130$ & 20 & 627 & 1.8 & 1.5 & 2.7 & 4.6 & 7.2 \\
\hline PD507 & $70 / 70$ & 8 & 614 & 1.6 & 1.1 & 6.1 & 12.3 & 23.0 \\
\hline PD508 & $262 / 262$ & 8 & 612 & 1.0 & 1.1 & 13.5 & 24.4 & 37.4 \\
\hline PD509 & $262 / 262$ & 15 & 614 & 0.8 & 1.0 & 18.4 & 31.4 & 45.7 \\
\hline
\end{tabular}

One of the most striking aspects of the results shown in Table IV is the insensitivity of SA to impeller speed, and to a certain extent, the rate at which the RA is added to the reactor. Only when the rate of addition of RA was slowed so that it took 20 seconds to add all the RA to the reactor did the SA show any significant change. This result is in keeping with our earlier hypothesis that the spherical nodules are formed rapidly after nucleation, and therefore they depend strongly on the chemical conditions and less strongly on the mixing speed, assuming that mixing is sufficiently strong so that there are no steep concentration gradients present.

Tap density also appears to be relatively insensitive to impeller speeds and RA addition times in Table IV. For PD501-507, all the TD values are in the range of 1.4-1.8 g/cc, despite significant changes in both the impeller speed and the rate of addition of RA. Although PD508 and 509 were both run at conditions similar to previous experiments, they both have much lower TD (PD508 is within specifications). Possible explanations and interpretations of these results are given after discussing some of the details for specific experiments.

The first experiment, PD501, was carried out using conditions that correspond to a constant power/volume scale-up of PD422, which was performed in the geometrically scaleddown round-bottomed glass reactor at AL. An important problem that arose in the course of this experiment was that the snorkel hood vent gate was left open when the Pd intermediate was being added to the reactor. A post-experiment accounting of Pd showed a deficit of approximately 50 grams, and it is possible that some intermediate was carried out of the reactor through the snorkel hood as it was being added through the hand-hole. This explanation is not implausible, as the draw on the snorkel hood is quite strong. Another problem that arose in this experiment is that some of the Pd intermediate settled into the exit pipe (the elbow at the bottom of the reactor) and never dissolved, further lowering the concentration of $\mathrm{Pd}$ intermediate prior to the precipitation reaction.

In PD502 the problem of Pd intermediate escaping through the snorkel hood was avoided by keeping the vent gate on the exhaust line closed while adding the Pd intermediate. However, this experiment (as well as PD503 and 504) was performed in a "dirty" reactor. After PD501 was performed, the reactor walls, impeller, and part of the baffle were washed using a water sprayer that was inserted through the reactor hand-hole. However, not all surfaces inside the reactor were accessible by this means, and it was later discovered that a significant amount of Pd metal remained coating various surfaces (especially the back side of the concave baffle). 
Previous experience conducting Pd precipitation in bench-scale dirty reactors showed that such coatings interfere with the repeatability of experiments, probably due to heterogeneous nucleation on the dirty surfaces. Because of these problems, we consider the results from PD501-504 to be unreliable.

Prior to PD505 and for all subsequent batches, the reactor cover was removed using a gantry and hoist to allow access for complete cleaning of the reactor prior to performing an experiment. A new Teflon plug was also made and used to displace dead volume in the reactor exit pipe, thereby eliminating the problem of having undissolved Pd intermediate in the bottom elbow of the reactor during the precipitation reaction. A comparison of the results for batches PD505-509 does suggest that increasing the mixing rate results in lower TD, however more experiments are required to justify this conclusion.

Lastly, we note that another possible explanation exists for why the TD is significantly lower in PD508 and 509 than in the other experiments. It was noted by Bob Malstrom and David Baldwin that the procedure for heating the RA solution to $60^{\circ} \mathrm{C}$ prior to adding it to the reactor may lead to decomposition of the sodium formate/formic acid solution. For the AL bench-scale experiments, the RA solution was heated using a water-recirculating bath set to the temperature used for the precipitation reaction. For the PD301-318 bench-scale experiments, the RA was easily heated to the required temperature using a hot plate at moderate temperatures. However, in order to effect heating of the RA solution in the same amount of time at the larger volumes used for the Pfaudler reactor, the hot plate must be set at a much higher temperature due to the smaller surface area/volume ratio. In order to avoid the possibility of decomposing the RA during heating, the solution was heated much more slowly for PD508, and a waterrecirculating bath was used to heat the solution for PD509. In both cases, the maximum temperature in the solution was probably lower than in all previous experiments (PD501-507). The fact that the Microtrac PS values for PD508 and 509 are within the SR specifications while those for PD501-507 are all out of specification also indicates a significant difference in the reaction conditions for PD508 and 509 compared to those for batches PD501-507.

SEM Photomicrographs for Pfaudler Reactor Batches:

The Pd powder produced in the Pfaudler experiments was assessed by the usual method of examining samples by SEM at SR to determine the nodule size, uniformity, and morphology. For a number of batches (including PD502-504 done using a "dirty" reactor), there is evidence of a bimodal distribution of nodule sizes in the SEM photomicrographs, with small and large nodules comprising the clusters of Pd. An example of this is shown in Figure 5 for batch PD506. The SEM images for PD506 clearly show a broad distribution of sizes of the primary spherical Pd particles (nodules or "grapes"), with the individual clusters generally comprised of either very small but relatively uniform-sized nodules or larger, relatively uniform-sized nodules. The large variation in primary particle sizes and the manner in which these primary particles are agglomerated suggest that nucleation and aggregation did not occur homogeneously in the reactor. This is not particularly surprising, since the RA solution was introduced into the reactor over a large time interval (20 seconds), thereby leading to a wide distribution of nuclei "birthdates". For some batches, there is also evidence of a bimodal distribution of sizes within a cluster, with some small nodules and some large nodules agglomerated in the same cluster. In contrast, the SEM photomicrographs for PD508 in Figure 5 show Pd nodules that are more 
uniform in size. The clusters are comprised of nodules that are not exactly the same size (some are slightly smaller or slightly larger than average), but the dispersion in sizes is much less than that for PD506. For PD508 (which met the SR specifications for TD, BET SA, and Microtrac PS), the RA solution was added over a shorter time interval (8 seconds) and a faster mixing speed $(262 \mathrm{rpm})$ was used. This combination of processing conditions is expected to result in the production of Pd powder having a more uniform nodule size.

\section{Concluding Remarks / Recommendations}

Reductive precipitation of Pd metal from diamminedichloropalladium using sodium formate/formic acid in a semi-batch, stirred-tank reactor is a complex process that depends sensitively on both the reaction chemistry (reactant concentrations, temperature, $\mathrm{pH}$, overall ionic strength, etc.) and on the details of mixing (including how the reductant is added to the reactor). Specific recommendations for further scale-up of this process that pertain to these two important categories are discussed below.

\section{Reaction Chemistry}

- Both the AL and ISU groups found that the two primary product specifications, TD and SA, depend sensitively on the solution $\mathrm{pH}$ in the precipitation reactor immediately prior to adding the RA. In this regard, extreme care should be taken in following the protocol for preparing the $\mathrm{Pd}$ intermediate as well as in making small adjustments to the solution $\mathrm{pH}$ using $\mathrm{HCl}$ before adding the $\mathrm{RA}$. In particular, the $\mathrm{HCl}$ should be added only in very small increments to adjust the $\mathrm{pH}$ to the range of 7.2 - 7.3. If too much $\mathrm{HCl}$ is added, the $\mathrm{Pd}$ intermediate will precipitate, $\mathrm{NH}_{4} \mathrm{OH}$ will have to be added to redissolve it, and more $\mathrm{HCl}$ will be needed to adjust the $\mathrm{pH}$ once again. These extra steps, if performed, change the total ionic strength of the solution in the reactor, thereby changing the resulting product TD and SA.

- In the PD301-318 bench-scale experiments, it was possible to quickly heat the relatively small volume of RA solution uniformly to the reaction temperature using a hot plate and stirrer. However, at larger scales (Pfaudler reactor), the volume of RA solution needed is on the order of a couple of liters. Heating this volume of solution to $60^{\circ} \mathrm{C}$ in a reasonable time on a hot plate requires a much higher hot-plate temperature, which may be sufficiently high so that even with vigorous stirring the temperature near the bottom of the vessel exceeds the temperatures at which sodium formate and/or formic acid are thermally stable, approximately $90^{\circ} \mathrm{C}$. (Experimentally, the problem arises because sodium formate settles to the bottom of the vessel, forming a layer of undissolved material that prevents normal function of the stirring bar.) Sodium formate likely decomposes into sodium oxalate, sodium carbonate, and hydrogen. Formic acid decomposes into $\mathrm{CO}$ and water. As a consequence, the entire solution chemistry would be altered. In order to avoid this pitfall, the RA solution should be heated to the reaction temperature using a water-recirculating bath held at a temperature below $90^{\circ} \mathrm{C}$.

- The first step in carrying out the precipitation reaction in the Pfaudler reactor involves heating water to the reaction temperature. This heating is accomplished by use of the reactor steam jacket (and stirrer), but this process takes hours. Typically, but not always, the vent was kept closed to speed the heating. In cases when the vent was left open, it may be possible that enough water evaporated prior to addition of the Pd intermediate that the actual 
concentration of Pd intermediate was slightly higher than intended. In addition, condensation in the vent line may take place. Condensate dripping back into the reactor may carry impurities, particularly if the vent line is constructed of easily corroded material. After the first experiment, the reactor vent was kept closed during the process of adding the $\mathrm{Pd}$ intermediate powder to the reactor in order to avoid having powder carried out through the hood. In general, the reactor hood should be used only when there is a possibility of gases evolving from the mixture (once the $\mathrm{NH}_{4} \mathrm{OH}$ is added to the reactor and during all subsequent steps), and the vent line should be constructed of non-corrosive material to avoid contaminating the reactor.

- Contamination of the Pd produced in the Pfaudler reactor may also result from corrosion observed for the stainless steel fittings at the bottom of the reactor (the bottom elbow, tubing, and ball valve). All reactor components that are exposed to the reaction solution should be glass-lined or Teflon-coated or constructed from materials such as polyethylene or Teflon, if possible, to minimize contamination of the Pd product.

- The dissolution of Pd intermediate is a slow process, and it is difficult to visually determine when complete dissolution has occurred in an industrial reactor. This problem is exacerbated by the presence of inlet/outlet ports, where fluid mixing may be inefficient or nonexistent. Plugs should be used to displace all dead volumes where Pd intermediate might become trapped.

\section{Mixing Considerations}

Although bench-scale experiments carried out at AL showed that the product TD is sensitive to impeller speed, this effect has not yet been observed in the Pfaudler reactor. For batch PD508 (which met specifications), mixing conditions were used that had been investigated previously (without meeting specifications). It seems probable that the difference in PD508 from previous runs is due to the different heating method used for dissolving the RA.

Surface area appears to be almost insensitive to mixing speed in the Pfaudler experiments carried out to date, but SA is influenced by the rate of addition of RA. Furthermore, it seems probable that the polydispersity in the sizes of the primary particles (nodules) is greatly influenced by the rate of addition of RA and also by the impeller speed. Because both precipitation and reduction of Pd intermediate ensue almost instantaneously after addition of RA, it is possible that the nodules are formed so rapidly inside a plume of RA that no amount of mixing will ensure that nucleation and growth of the nodules occurs homogeneously in the reactor. If this is indeed the case, it should be expected that the heterogeneity in the sizes of the nodules will increase upon scale-up of the process. In view of the above considerations, we make the following recommendations:

- Since the SA depends directly upon the number of nuclei formed that grow to become nodules, great care should be taken to introduce the RA over the prescribed time interval. The reactor should be agitated as vigorously as possible while the RA is being added to reduce spatial gradients in chemical composition. 
- After the RA has been added to the reactor, subsequent mixing plays a role in governing the rate of agglomeration (and breakup) of the nodules. Changes in impeller speed may result in small changes in TD, but the connection does not appear to be strong. Increasing impeller speed promotes aggregation, which results in lower TD, but it also increases the likelihood of particle breakup - this may explain why impeller speed has not been particularly effective in changing the final TD of the Pd powder from the Pfaudler reactor experiments.

- Further scale-up of the precipitation process to the $100+$ gallon level will likely require some modifications to the reactor and to the procedures. Because the non-uniform energy dissipation in a stirred-tank reactor is worsened at larger scales, it may be necessary to employ multiple impellers. Furthermore, the RA could be more effectively dispersed in the reactor (and thereby promote a monodisperse nodule size) by using multiple feed ports with exits located near the tips of the multiple impellers.

\section{Acknowledgments}

Ames Laboratory is operated for the U.S. Department of Energy by Iowa State University, under contract number W-7405-Eng-82. The authors thank Robert Terpstra and Dave Garbett at AL for performing TD analyses on the Pd powder samples, Dr. Stan Bajic at AL for performing the IR-photoacoustic analyses on the $\mathrm{Pd}\left(\mathrm{NH}_{3}\right)_{2} \mathrm{Cl}_{2}$ intermediate samples, and Fran Laabs at AL for performing SEM analysis of the Pd powder from the stopped-flow reactions.

\section{References}

1) D. P. Baldwin and D. S. Zamzow, "Wet Processing of Palladium for Use in the Tritium Facility at Westinghouse, Savannah River, SC: Preparation of Palladium using the Mound Muddy Water Process," Ames Laboratory Report IS-5134, November, 1998.

2) D. P. Baldwin and D. S. Zamzow, "Wet Processing of Palladium for Use in the Tritium Facility at Westinghouse, Savannah River, SC: Preparation of Palladium using the Sandia / LANL Process," Ames Laboratory Report IS-5137, November, 1999.

3) D. P. Baldwin and D. S. Zamzow, "Wet Processing of Palladium for Use in the Tritium Facility at Westinghouse, Savannah River, SC: Preparation of Palladium using the Sandia / LANL Process during FY00,” Ames Laboratory Report IS-5143, December, 2000 . 
Table 1. Palladium Powder Specifications

\begin{tabular}{|c|c|c|}
\hline & Specifications & \\
\hline Tap density & $0.9-1.2$ & $\mathrm{~g} / \mathrm{cc}$ \\
\hline BET surface area & $0.9-1.2$ & $\mathrm{~m}^{2} / \mathrm{g}$ \\
\hline \multicolumn{3}{|l|}{ Microtrac particle size } \\
\hline $25 \%<$ & $10-26$ & $\mu \mathrm{m}$ \\
\hline $50 \%<$ & $21-47$ & $\mu \mathrm{m}$ \\
\hline $75 \%<$ & $30-67$ & $\mu \mathrm{m}$ \\
\hline Nodule size & $0.3-0.8$ & $\mu \mathrm{m}$ \\
\hline \multicolumn{3}{|l|}{ Chemical impurities } \\
\hline $\mathrm{C}$ & $<100$ & wppm \\
\hline $\mathrm{S}$ & $<<5$ & wppm \\
\hline $\mathrm{N}$ & $<200$ & wppm \\
\hline $\mathrm{O}$ & $<1200$ & wppm \\
\hline $\mathrm{Cl}$ & $<150$ & wppm \\
\hline $\mathrm{B}, \mathrm{Si}, \mathrm{P}, \mathrm{Br}$ & $<50$ total & wppm \\
\hline $\mathrm{Na}, \mathrm{K}$ & $<100$ total & wppm \\
\hline $\mathrm{Fe}, \mathrm{Cr}, \mathrm{Ni}, \mathrm{Mo}$ & $<60$ total & wppm \\
\hline $\mathrm{Pt}, \mathrm{Rh}, \mathrm{Ru}, \mathrm{Os}, \mathrm{Ir}, \mathrm{Au}, \mathrm{Ag}$ & $<1500$ total & wppm \\
\hline $\begin{array}{c}\text { As, } \mathrm{Cd}, \mathrm{Sn}, \mathrm{Sb}, \mathrm{Pb}, \mathrm{Bi}, \mathrm{Hg} \text {, } \\
\text { Tl, } \mathrm{Zn}, \mathrm{Cu}\end{array}$ & $<50$ each, $<100$ total & wppm \\
\hline All other elements-GDMS & & wppm \\
\hline $\begin{array}{c}\text { All other elements - } \\
\text { ICPMS }\end{array}$ & $<10$ each, $<100$ total & wppm \\
\hline
\end{tabular}


Table II. Reaction Conditions and Analysis Results for Palladium Processing Batches PD301-318

\begin{tabular}{|c|c|c|c|c|c|c|c|c|c|c|c|c|c|}
\hline Batch & $\begin{array}{r}\text { DADC-Pd } \\
(\mathrm{g})\end{array}$ & $\begin{array}{r}\mathrm{NH} 4 \mathrm{OH} \\
(\mathrm{mL})\end{array}$ & $\begin{array}{r}\text { Formic } \\
\text { acid } \\
(\mathrm{mL}) \\
\end{array}$ & $\begin{array}{r}\text { Sodium } \\
\text { formate } \\
(\mathrm{g}) \\
\end{array}$ & $\begin{array}{r}\mathrm{RA} / \mathrm{Pd} \\
\text { mol.ratio }\end{array}$ & $\begin{array}{r}\mathrm{Pd} \text { conc } \\
\text { [initial] } \\
(\mathrm{M}) \\
\end{array}$ & $\begin{array}{r}\text { mol.frac. } \\
\text { Formic A. }\end{array}$ & $\begin{array}{r}\text { Beaker } \\
\text { size }\end{array}$ & $\begin{array}{r}\text { Pd sol'n } \\
\text { init. vol. } \\
(L) \\
\end{array}$ & $\begin{array}{r}\text { Temp. } \\
\left({ }^{\circ} \mathrm{C}\right)\end{array}$ & initial & $\begin{array}{l}\text { Solution } \mathrm{pH} \dagger \\
\text { after RA } \\
\text { addition }\end{array}$ & final \\
\hline PD301 & 137.8 & 80 & 40.5 & 141.7 & 4.65 & 0.52 & 0.31 & $2 \mathrm{~L}$ & 1.26 & 60 & 7.3 & N.M. & 8.7 \\
\hline PD302 & 223.5 & 129 & 36.0 & 228.0 & 3.96 & 0.50 & 0.20 & $4 \mathrm{~L}$ & 2.13 & 61 & 7.2 & N.M. & 8.3 \\
\hline PD303 & 224.1 & 129 & 36.0 & 228.0 & 3.95 & 0.50 & 0.20 & $4 \mathrm{~L}$ & 2.13 & 63 & 7.2 & 5.3 & 8.5 \\
\hline PD304 & 44.8 & 26 & 7.3 & 45.6 & 3.97 & 0.10 & 0.20 & $4 \mathrm{~L}$ & 2.13 & 61 & 7.5 & 5.3 & 8.3 \\
\hline PD305 & 44.8 & 26 & 7.1 & 45.6 & 3.94 & 0.10 & 0.20 & $4 \mathrm{~L}$ & 2.13 & 60 & 7.4 & N.M. & 8.4 \\
\hline PD306 & 44.8 & 26 & 7.5 & 45.6 & 3.99 & 0.10 & 0.21 & $4 \mathrm{~L}$ & 2.13 & 60 & 7.4 & 5.3 & 8.4 \\
\hline PD307 & 44.9 & 27.5 & 7.5 & 45.6 & 3.98 & 0.10 & 0.21 & $4 \mathrm{~L}$ & 2.13 & 60 & 7.1 & N.M. & 8.1 \\
\hline PD308 & 45.1 & 25 & 7.5 & 45.7 & 3.97 & 0.10 & 0.21 & $4 \mathrm{~L}$ & 2.13 & 59.5 & 7.1 & N.M. & 8.2 \\
\hline PD309 & 44.9 & 29 & 7.5 & 45.1 & 3.94 & 0.10 & 0.21 & $4 \mathrm{~L}$ & 2.13 & 60 & 6.9 & 5.3 & 8.3 \\
\hline PD310 & 44.8 & 25 & 7.5 & 45.0 & 3.95 & 0.10 & 0.21 & $4 \mathrm{~L}$ & 2.13 & 59 & 7.0 & 3.5 & 7.6 \\
\hline PD311 & 50.3 & 28 & 8.1 & 51.4 & 3.97 & 0.10 & 0.20 & $4 \mathrm{~L}$ & 2.35 & 60 & 7.3 & N.M. & 8.4 \\
\hline PD312 & 50.3 & 31 & 8.3 & 74.8 & 5.44 & 0.40 & 0.15 & $1 \mathrm{~L}$ & 0.59 & 60 & 7.3 & N.M. & 8.3 \\
\hline PD313 & 169.8 & 100 & 27.3 & 173.5 & 3.97 & 0.40 & 0.20 & $4 \mathrm{~L}$ & 1.99 & 60 & 7.3 & N.M. & 8.4 \\
\hline PD314 & 50.3 & 28 & 8.1 & 51.4 & 3.97 & 0.10 & 0.20 & $4 \mathrm{~L}$ & 2.35 & 60 & 7.3 & N.M. & 8.3 \\
\hline PD315 & 50.3 & 30 & 8.0 & 51.4 & 3.96 & 0.40 & 0.20 & $1 \mathrm{~L}$ & 0.59 & 60 & 7.3 & N.M. & 8.4 \\
\hline PD316 & 169.8 & 100 & 27.3 & 173.5 & 3.97 & 0.40 & 0.20 & $4 \mathrm{~L}$ & 1.99 & 60 & 7.3 & 5.3 & 8.4 \\
\hline PD317 & 227.1 & 131 & 41.9 & 224.0 & 3.98 & 0.50 & 0.23 & $4 \mathrm{~L}$ & 2.13 & 60 & 7.2 & N.M. & 8.6 \\
\hline PD318 & 189.0 & 109.6 & 35.0 & 186.8 & 3.98 & 0.50 & 0.23 & $4 \mathrm{~L}$ & 1.78 & 60 & 7.2 & N.M. & 8.4 \\
\hline
\end{tabular}

$\dagger$ The $\mathrm{pH}$ meter/electrode was calibrated at room temperature; solution pH measurements were made at the reaction temperature, and are not temperature-corrected.

† Some concentrated $\mathrm{HCl}$ (generally $\sim 0.5-1 \mathrm{~mL}$ ) was added to the solution to adjust the initial $\mathrm{pH}$ prior to the precipitation reaction.

\begin{tabular}{|c|c|c|c|c|c|c|c|c|c|c|c|c|c|c|c|}
\hline Batch & $\begin{array}{c}\text { Incubat'n } \\
\text { time } \\
\text { (min) }\end{array}$ & $\begin{array}{l}\text { Bubbling i } \\
\text { start } \\
\text { (min }\end{array}$ & $\begin{array}{l}\text { solution } \\
\text { end } \\
\text { sec) }\end{array}$ & $\begin{array}{l}\text { Mixing } \\
\text { method }\end{array}$ & $\begin{array}{l}\text { Mixing } \\
\text { time } \\
\text { (min) }\end{array}$ & $\begin{array}{l}\text { Mixing } \\
\text { rate } \\
\text { (rpm) }\end{array}$ & $\begin{array}{c}\text { RA Solution } \\
\text { volume / add. time }\end{array}$ & $\begin{array}{r}{ }^{*} \mathrm{Pd} \\
\text { precipitate } \\
(\mathrm{g})\end{array}$ & $\begin{array}{r}\text { 100mesh } \\
\mathrm{Pd} \\
(\mathrm{g})\end{array}$ & $\begin{array}{r}\text { Tap D. } \\
(\mathrm{g} / \mathrm{cc}) \\
{[0.9-1.2]}\end{array}$ & $\begin{array}{r}\text { S. Area } \\
\left(\mathrm{m}^{2} / \mathrm{g}\right) \\
{[0.9-1.2]}\end{array}$ & $\begin{array}{r}\text { Micro } \\
\text { d25 } \\
{[10-26]}\end{array}$ & $\begin{array}{r}\text { rac size } \\
d 50 \\
{[21-47]}\end{array}$ & 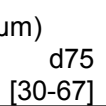 & Date \\
\hline PD301 & $0: 15$ & $1: 45$ & $>2: 30$ & off-c mix & 30 & 500 & $276 \mathrm{~mL} / 60 \mathrm{sec}$ & 67.9 & 55.5 & 1.15 & 0.66 & 36.2 & 63.4 & 95.4 & $6 / 9 / 99$ \\
\hline PD302 & $0: 12$ & $0: 45$ & $1: 21$ & off-c mix & 30 & 330 & $444 \mathrm{~mL} / 12 \mathrm{sec}$ & 108.4 & - & 1.07 & 0.94 & 16.8 & 30.5 & 45.1 & $7 / 15 / 99$ \\
\hline PD303 & $0: 03$ & $1: 00$ & N.M. & off-c mix & 30 & 330 & $444 \mathrm{~mL} / 8 \mathrm{sec}$ & 107.3 & - & 1.02 & 0.91 & 20.3 & 37.4 & 57.2 & $7 / 21 / 99$ \\
\hline PD304 & 0:05 & $2: 30$ & $<3: 00$ & off-c mix & 30 & $500 / 80$ & $444 \mathrm{~mL} / 12 \mathrm{sec}$ & 20.8 & - & 1.22 & 0.69 & 16.4 & 30.2 & 47.4 & $8 / 10 / 99$ \\
\hline PD305 & 0:02 & $2: 55$ & N.M. & centered & 30 & 317 & $444 \mathrm{~mL} / 8 \mathrm{sec}$ & - & - & 1.18 & 0.83 & 11.7 & 21.5 & 35.7 & 9/8/99 \\
\hline PD306 & $0: 06$ & $4: 15$ & N.M. & off-c mix & 30 & 554 & $444 \mathrm{~mL} / 8 \mathrm{sec}$ & - & - & 1.53 & 0.52 & 19.7 & 34.4 & 54.2 & 9/16/99 \\
\hline PD307 & 0:01 & $2: 00$ & $>3: 45$ & off-c mix & 30 & 634 & $444 \mathrm{~mL} / 8 \mathrm{sec}$ & 18.8 & - & 1.08 & 0.77 & 20.9 & 42.4 & 72.5 & $11 / 18 / 99$ \\
\hline PD308 & $0: 08$ & $2: 14$ & $3: 45$ & off-c mix & 30 & 634 & $444 \mathrm{~mL} / 8 \mathrm{sec}$ & 11.5 & - & 1.18 & 0.61 & 23.1 & 49.2 & 89.6 & $11 / 25 / 99$ \\
\hline PD309 & 0:06 & $2: 25$ & $4: 10$ & off-c mix & 30 & 475 & $444 \mathrm{~mL} / 8 \mathrm{sec}$ & 18.9 & 18.4 & 0.78 & 0.65 & 28.3 & 45.6 & 66.6 & $12 / 16 / 99$ \\
\hline PD310 & $0: 01$ & 0:09 & $2: 25$ & off-c mix & 30 & 634 & $444 \mathrm{~mL} / 0.5 \mathrm{sec}$ & 21.2 & 20.3 & 0.53 & 2.20 & 9.0 & 15.8 & 24.7 & $1 / 20 / 00$ \\
\hline PD311 & $0: 09$ & $2: 00$ & $3: 10$ & off-c mix & 30 & 396 & $100 \mathrm{~mL} / 9 \mathrm{sec}$ & 22.6 & 19.2 & 1.10 & 0.94 & 15.7 & 30.9 & 51.2 & $2 / 11 / 00$ \\
\hline PD312 & $0: 00^{* *}$ & $0: 40$ & $1: 25$ & off-c mix & 30 & 475 & $100 \mathrm{~mL} / 8 \mathrm{sec}$ & 24.5 & 23.4 & 0.85 & 0.85 & 28.4 & 48.2 & 74.8 & $2 / 16 / 00$ \\
\hline PD313 & $0: 00^{* *}$ & $0: 48$ & $2: 00$ & off-c mix & 30 & 317 & $338 \mathrm{~mL} / 11 \mathrm{sec}$ & 84.1 & 80.1 & 1.04 & 0.85 & 19.3 & 34.7 & 54.7 & $2 / 24 / 00$ \\
\hline PD314 & $0: 00^{* *}$ & $2: 14$ & $2: 55$ & off-c mix & 30 & 396 & $100 \mathrm{~mL} / 9 \mathrm{sec}$ & 22.9 & 21.5 & 1.20 & 0.94 & 13.3 & 24.5 & 40.7 & $3 / 23 / 00$ \\
\hline PD315 & $0: 00^{\star \star}$ & $1: 10$ & $1: 45$ & off-c-mix & 30 & 475 & $100 \mathrm{~mL} / 12 \mathrm{sec}$ & 24.6 & 23.4 & 0.95 & 0.79 & 22.5 & 39.3 & 58.3 & $4 / 5 / 00$ \\
\hline PD316 & $0: 00^{* *}$ & $1: 00$ & $1: 48$ & off-c-mix & 30 & 317 & $338 \mathrm{~mL} / 10 \mathrm{sec}$ & 82.9 & 79.8 & 0.99 & 0.71 & 24.3 & 42.0 & 63.3 & $4 / 11 / 00$ \\
\hline PD317 & $0: 00^{\star *}$ & 0:38/1:10‡ & N.M. & off-c-mix & 30 & $200 / 114$ & $226 \mathrm{~mL} / 8 \mathrm{sec}$ & 109.1 & 103.1 & 1.09 & 0.96 & 13.7 & 26.6 & 45.9 & $5 / 17 / 00$ \\
\hline $317-2$ & & & & & & & & & & 1.13 & 0.92 & 13.3 & 26.4 & 46.2 & \\
\hline PD318 & $0: 00^{\star *}$ & $0: 45 / 1: 14 \ddagger$ & 1:03/1:20 & centered & 30 & $220 / 114$ & $189 \mathrm{~mL} / 9 \mathrm{sec}$ & 92 & 89.1 & 0.90 & 0.77 & 22.1 & 41.0 & 66.6 & $5 / 20 / 00$ \\
\hline $318-2$ & & & & & & & & & & 0.85 & 0.74 & 21.5 & 38.5 & 59.3 & \\
\hline
\end{tabular}

PD304 Mixer stopped and had to be restarted at lower speed; the reaction appeared to be near completion.

PD308 was done using a dirty reactor (Pd coating was not removed prior to reaction). A lot of palladium precipitated as bright $\mathrm{Pd}$ on the reactor walls.

* PD301-310 Mass of Pd precipitate does not include Pd coated to reactor or mixer paddle.

** PD312-318 Solution darkening was immediately observed.

‡ PD317-318 Two distinct periods of bubbling were observed. Also, two different sieving procedures were used on each sample. 
Table III. Reaction Conditions and Analysis Results for Palladium Processing Batches PD501-509

\begin{tabular}{|c|c|c|c|c|c|c|c|c|c|c|c|c|c|c|}
\hline Batch & $\begin{array}{r}\text { DADC-Pd } \\
(\mathrm{g})\end{array}$ & $\begin{array}{r}\mathrm{NH} 4 \mathrm{OH} \\
(\mathrm{mL})\end{array}$ & $\begin{array}{r}\text { Formic } \\
\text { acid } \\
(\mathrm{mL})\end{array}$ & $\begin{array}{r}\text { Sodium } \\
\text { formate } \\
\text { (g) }\end{array}$ & $\begin{array}{r}\mathrm{RA} / \mathrm{Pd} \\
\text { mol.ratio }\end{array}$ & $\begin{array}{r}\text { Pd conc } \\
\text { [initial] }{ }^{*} \\
(\mathrm{M})\end{array}$ & $\begin{array}{l}\text { mol.frac. } \\
\text { Formic A. }\end{array}$ & Reactor & $\begin{array}{r}\text { Pd sol'n } \\
\text { init. vol. } \\
(\mathrm{L})\end{array}$ & $\begin{array}{r}\text { Approx. } \\
\text { final vol. } \\
(\mathrm{L})\end{array}$ & $\begin{array}{r}\text { Temp. } \\
\left({ }^{\circ} \mathrm{C}\right)\end{array}$ & initial & $\begin{array}{l}\text { Solution } \mathrm{pH} \dagger \\
\text { after } \mathrm{RA} \\
\text { addition }\end{array}$ & final \\
\hline PD501 & 1247 & 727 & 256.4 & 1195.4 & 3.99 & 0.10 & 0.254 & Pfaudler & $\begin{array}{r}12 \\
59.0\end{array}$ & 61.5 & 60 & 7.24 & N.M. & $\sim 8$ \\
\hline PD502 & 1247 & 727 & 256.4 & 1195.4 & 3.99 & 0.10 & 0.254 & Pfaudler & 59.0 & 61.5 & 60 & 7.2 & N.M. & 8.04 \\
\hline PD503 & 1247 & 726 & 256.4 & 1195.4 & 3.99 & 0.10 & 0.254 & Pfaudler & 59.0 & 61.5 & 60 & $\sim 7.2$ & N.M. & $\sim 8.6$ \\
\hline PD504 & 1247 & 727 & 256.4 & 1195.7 & 3.99 & 0.10 & 0.254 & Pfaudler & 59.0 & 61.8 & 60 & 7.25 & N.M. & 8.36 \\
\hline PD505 & 1247 & 726 & 256.4 & 1195.7 & 3.99 & 0.10 & 0.254 & Pfaudler & 59.2 & 61.9 & 60 & 7.27 & N.M. & 8.4 \\
\hline PD506 & 1247 & 726 & 256.4 & 1195.7 & 3.99 & 0.10 & 0.254 & Pfaudler & 58.9 & 61.9 & 60 & 7.26 & N.M. & 8.34 \\
\hline PD507 & 1247 & 727 & 256.4 & 1197.7 & 4.00 & 0.10 & 0.253 & Pfaudler & 59.0 & 61.7 & 60 & 7.3 & N.M. & 8.5 \\
\hline PD508 & 1247 & 727 & 256.4 & 1197.7 & 4.00 & 0.10 & 0.253 & Pfaudler & 59.0 & 61.5 & 60 & 7.25 & N.M. & 8.4 \\
\hline PD509 & 1247.2 & 700 & 256.4 & 1197.7 & 4.00 & 0.10 & 0.253 & Pfaudler & 59.5 & 62.7 & 60 & 7.23 & N.M. & 8.4 \\
\hline
\end{tabular}

†The $\mathrm{pH}$ meter/electrode was calibrated at room temperature; solution $\mathrm{pH}$ measurements were made at reaction temperature, and are not temperature-corrected. * Unreacted intermediate was found in the reactor for PD501 and 502, so the initial concentration was less than $0.1 \mathrm{M}$ for these two batches. Since Pd intermediate was likely lost through the reactor exhaust vent line for PD501, the initial concentration was much less than $0.1 \mathrm{M}$.

\begin{tabular}{|c|c|c|c|c|c|c|c|c|c|c|c|c|c|c|c|}
\hline Batch & $\begin{array}{c}\text { Incubat'n } \\
\text { time } \\
\text { (min) }\end{array}$ & $\begin{array}{r}\text { Bubblir } \\
\text { start } \\
(1\end{array}$ & $\begin{array}{l}\text { solution } \\
\text { end } \\
\text { sec) }\end{array}$ & $\begin{array}{l}\text { Mixing } \\
\text { method }\end{array}$ & $\begin{array}{l}\text { Mixing } \\
\text { time } \\
\text { (min) }\end{array}$ & $\begin{array}{l}\text { Mixing } \\
\text { rate } \\
(\mathrm{rpm}) \\
\end{array}$ & $\begin{array}{c}\text { RA } \\
\text { volume } \\
* *(L) \\
\end{array}$ & $\begin{array}{r}\text { RA Addition Time } \\
\text { (pumped thru tube) }\end{array}$ & $\begin{array}{c}\mathrm{Pd} \\
\text { precipitate } \\
(\mathrm{g})\end{array}$ & $\begin{array}{r}\text { 100mesh } \\
\mathrm{Pd} \\
(\mathrm{g})\end{array}$ & $\begin{array}{r}\text { Tap D. } \\
\text { (g/cc) } \\
{[0.9-1.2]}\end{array}$ & $\begin{array}{r}\text { S. Area } \\
\left(\mathrm{m}^{2} / \mathrm{g}\right) \\
{[0.9-1.2]}\end{array}$ & $\begin{array}{r}\text { Micrc } \\
\text { d25 } \\
{[10-26]}\end{array}$ & $\begin{array}{r}\text { trac size } \\
\text { d50 } \\
{[21-47]} \\
\end{array}$ & $\begin{array}{l}\text { m) } \begin{array}{r}\text { d75 } \\
{[30-67]}\end{array} \\
\end{array}$ \\
\hline PD501 $\ddagger$ & 0.45 & $1: 42$ & $2: 33$ & Pfaudler PBT & $3 / 37$ & $130 / 70$ & 2.51 & $\sim 11.5 \mathrm{sec}$ & 577.1 & 382.2 & 1.7 & 1.2 & 4.1 & 6.9 & 11.0 \\
\hline PD502 & 0.17 & $1: 36$ & $2: 39$ & Pfaudler PBT & $3 / 27$ & $130 / 190$ & 2.51 & $\sim 11.5 \mathrm{sec}$ & 631.3 & 398.4 & 1.4 & 1.1 & 6.1 & 11.4 & 18.1 \\
\hline PD503 & 0.17 & $2: 07$ & $3: 30$ & Pfaudler PBT & $3 / 27$ & $130 / 262$ & 2.51 & $\sim 11.5 \mathrm{sec}$ & 632.4 & 558.2 & 1.5 & 1.0 & 8.5 & 15.3 & 24.3 \\
\hline PD504 & 0.25 & $1: 30$ & $2: 06$ & Pfaudler PBT & 30 & 262 & 2.77 & $\sim 11 \mathrm{sec}$ & 623 & 587 & 1.4 & 1.0 & 7.8 & 13.9 & 21.8 \\
\hline PD505 & 0.15 & $1: 43$ & $2: 57$ & Pfaudler PBT & 30 & 130 & 2.72 & $\sim 11 \mathrm{sec}$ & 622.5 & 583.4 & 1.6 & 1.2 & 6.6 & 13.7 & 24.9 \\
\hline PD506 & N.M. & $1: 39$ & $2: 24$ & Pfaudler PBT & 30 & 130 & 2.99 & $\sim 20 \mathrm{sec}$ & 627.4 & 534 & 1.8 & 1.5 & 2.7 & 4.6 & 7.2 \\
\hline PD507 & N.M. & $0: 57$ & $3: 00$ & Pfaudler PBT & 40 & 70 & 2.70 & †† $\sim 8 \mathrm{sec}$ & 614.4 & 341.2 & 1.6 & 1.1 & 6.1 & 12.3 & 23.0 \\
\hline PD508 & N.M. & $1: 45$ & N.M. & Pfaudler PBT & 30 & 262 & 2.51 & $\dagger \dagger \sim 8 \mathrm{sec}$ & 612 & 560 & 1.0 & 1.1 & 13.5 & 24.4 & 37.4 \\
\hline PD509 & N.M. & $2: 33$ & $3: 06$ & Pfaudler PBT & 30 & 262 & 3.15 & $\sim 15 \mathrm{sec}$ & 613.6 & 522.5 & 0.8 & 1.0 & 18.4 & 31.4 & 45.7 \\
\hline
\end{tabular}

\footnotetext{
¥ Only part $(393.7 \mathrm{~g})$ of the Pd precipitate was sieved for PD 501 . Other palladium was in the 2 nd filter bag, stuck in pipes, or otherwise unavailable at the time of sieving.

** Italicized entries are estimated values.

†† The reducing agent was poured in (not pumped) for PD507 and 508. The reported volume corresponds to the sum of the water and formic acid volumes. The actual solution
} volume is not reported. 


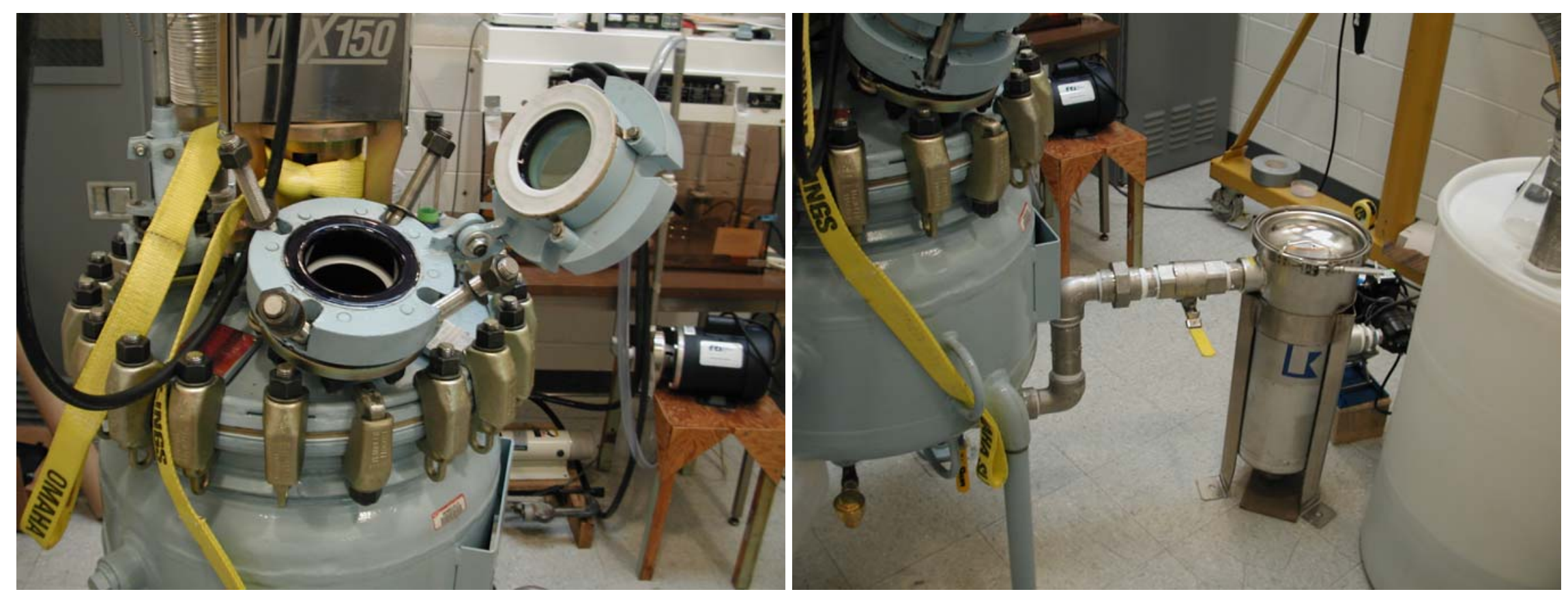

Figure 1. Photographs of the 20-gallon Pfaudler reactor (left) and the filtration apparatus connected to the reactor (right) for removal of $\mathrm{Pd}$ and reaction solution after performing a processing batch. 

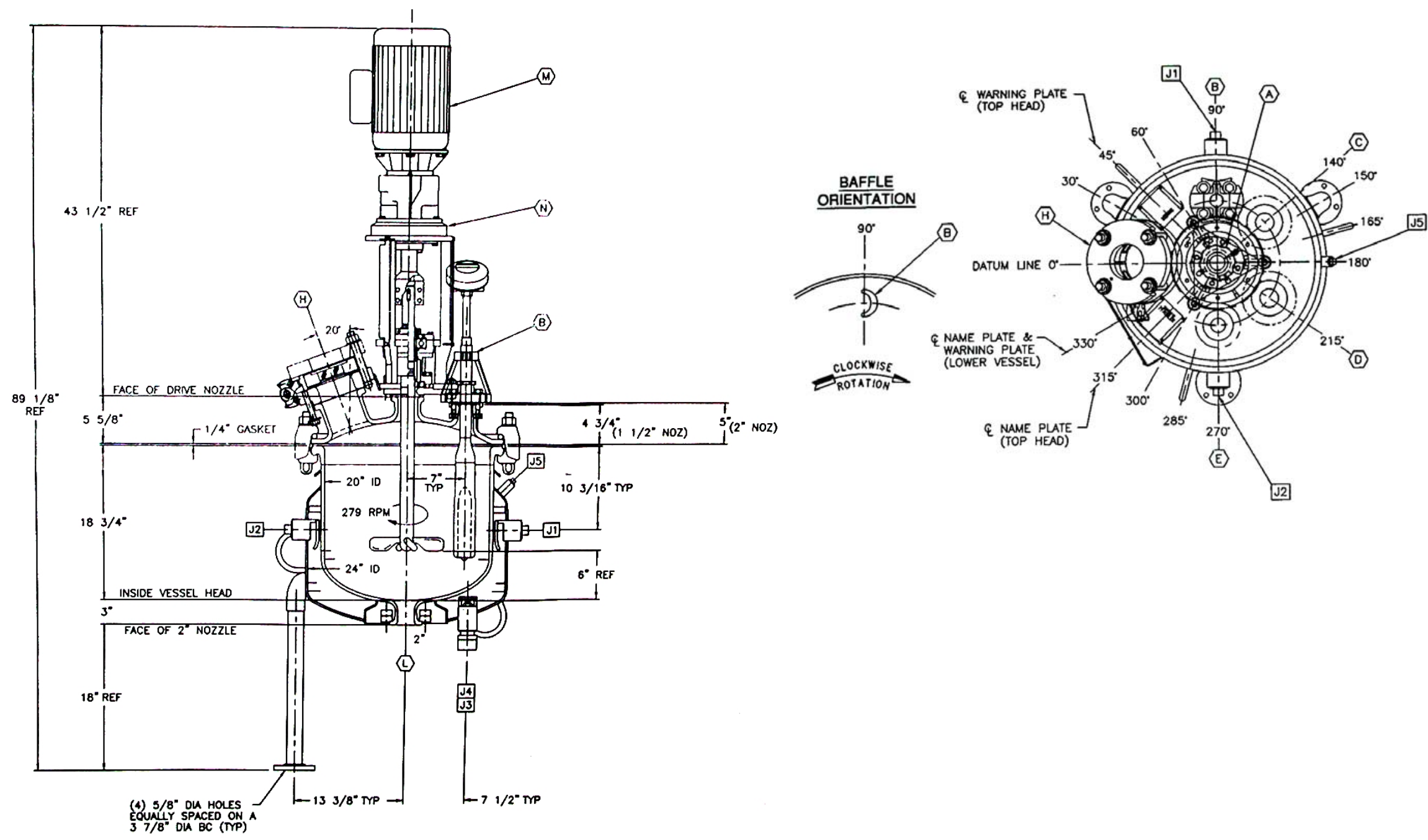

Figure 2. Design drawings for the 20-gallon Pfaudler reactor, showing the dimensions of the components of the reactor, motor drive, and motor (left) and a view of the top of the reactor, showing the positions of the ports (right). 


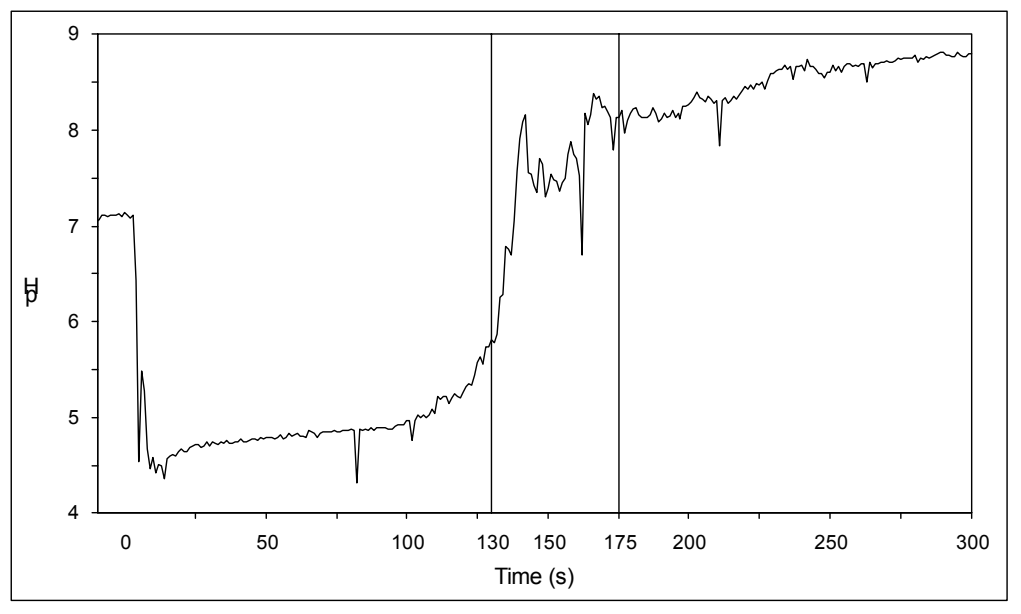

Figure 3. The $\mathrm{pH}$-monitor data for Pd processing batch PD602, showing the values measured during the first 5 minutes of the reaction. For this run, $\mathrm{pH}$ data were acquired at a rate of 1 point/second; time $=0$ corresponds to the start of RA addition. The vertical lines (at 130 and 175 seconds) mark the times at which bubbling-in-solution was observed to start and end for PD602.
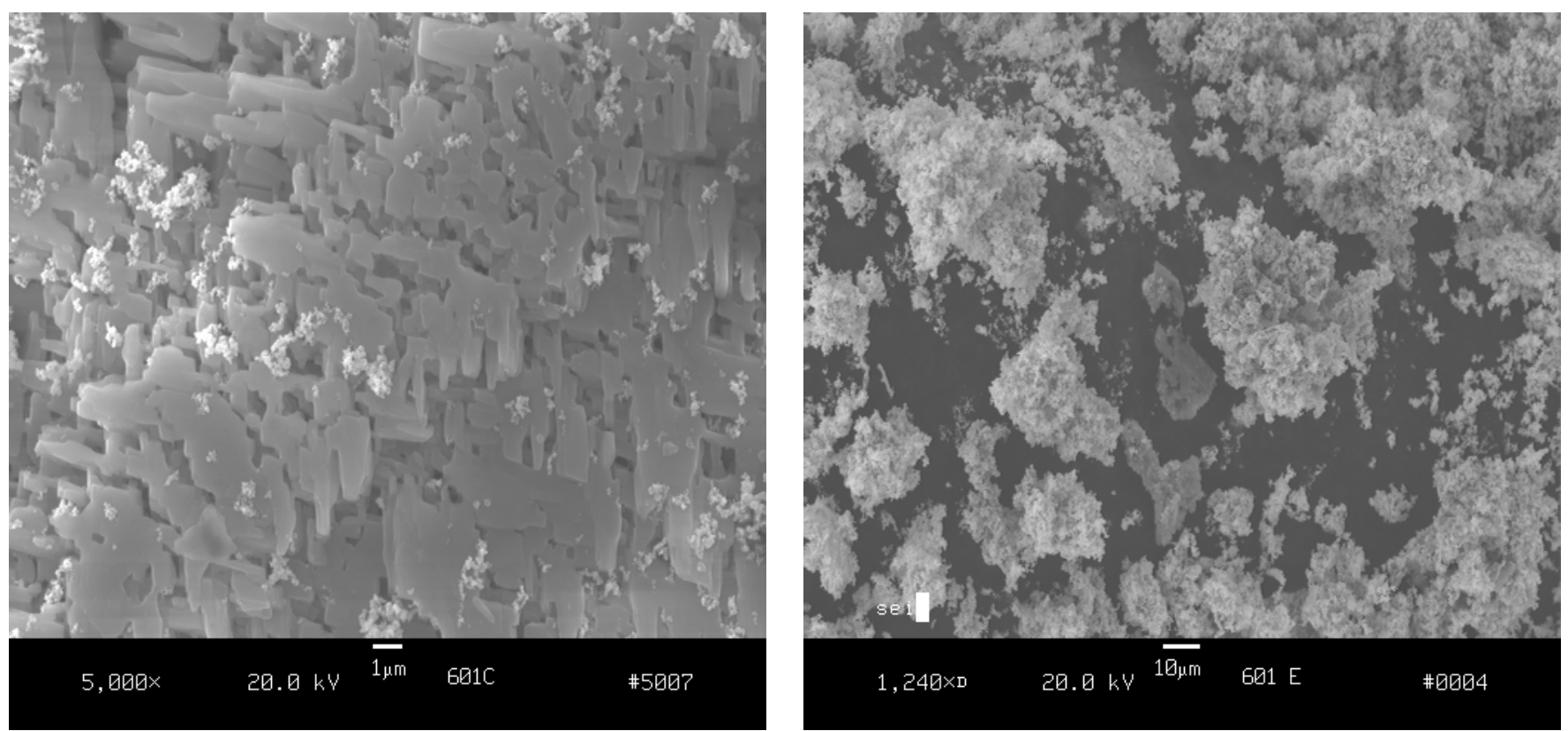

Figure 4. SEM photomicrographs for stopped-flow reactions (batch PD601), showing Pd particles formed at 15 seconds (left) and 60 seconds (right). On the left, the $\mathrm{Pd}$ is mixed (presumably) with unreacted intermediate, $\mathrm{Pd}\left(\mathrm{NH}_{3}\right)_{2} \mathrm{Cl}_{2}$, the larger sheet-like structures shown filling the background of the photomicrograph; for this sample, the isolated $\mathrm{Pd}$ was not rinsed with a dilute solution of $\mathrm{NH}_{4} \mathrm{OH}$ to remove $\mathrm{Pd}\left(\mathrm{NH}_{3}\right)_{2} \mathrm{Cl}_{2}$ present in the quenched $\mathrm{Pd}-\mathrm{RA}-\mathrm{H}_{2} \mathrm{O}_{2}$ reaction mixture. 

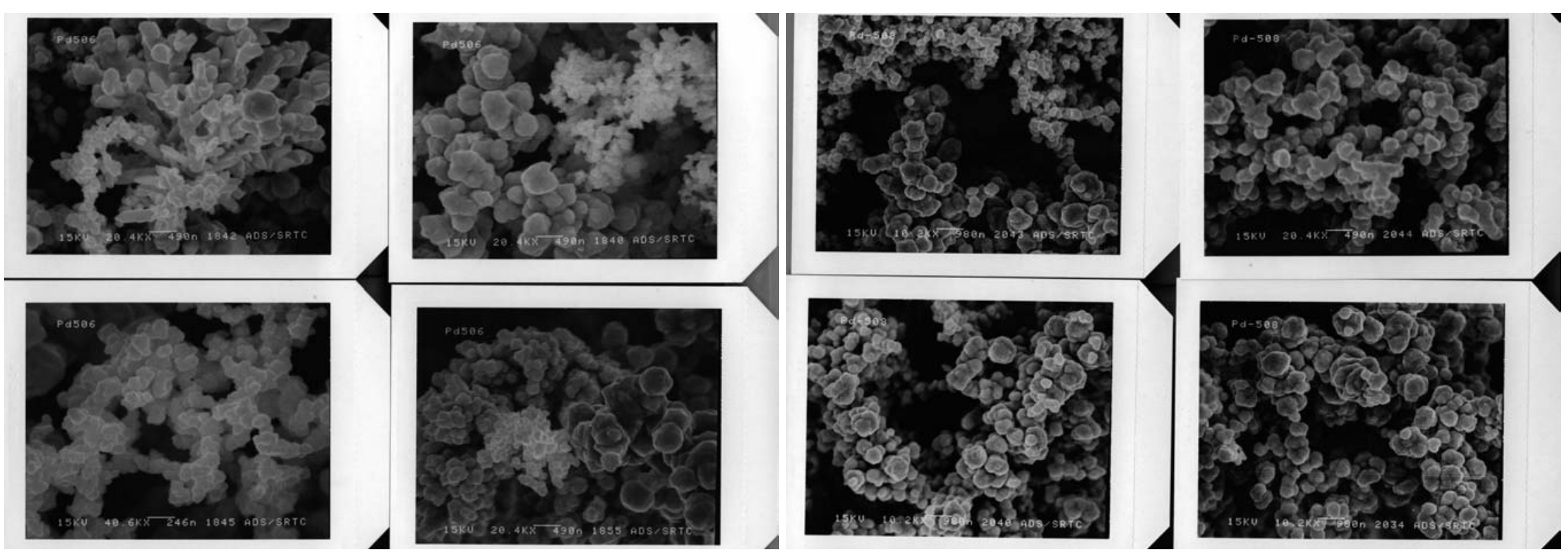

Figure 5. SEM photomicrographs for Pd processing batches PD506 (left) and PD508 (right) - see text for discussion. 


\section{Appendix A. ISU Preparation of Palladium Intermediate $\mathrm{Pd}\left(\mathrm{NH}_{3}\right)_{2} \mathrm{Cl}_{2}$}

Diamminedichloropalladium, $\mathrm{Pd}\left(\mathrm{NH}_{3}\right)_{2} \mathrm{Cl}_{2}$, is produced using the following procedure:

1. Aqua regia is prepared by combining $1600 \mathrm{~mL}$ of $\mathrm{HCl}$ and $900 \mathrm{~mL}$ of $\mathrm{HNO}_{3}$ in a 6-Liter Erlenmeyer flask inside a hood. The mixture is then allowed to stand for 30 minutes.

2. Approximately $350 \mathrm{~g}$ of $\mathrm{Pd}$ metal is then slowly added to the acid mixture. Vigorous bubbling ensues, particularly at the beginning of this addition process.

3. The flask is heated to boiling on a hot plate and stirred with a Teflon-coated magnetic stir bar. Boiling is continued until nearly all the liquid in the flask is gone. A rubber stopper fitted with two short tubes is used to cap the flask during this step. In order to hasten the boiling process and purge the evaporated gases, nitrogen from a gas cylinder is passed through one of the tubes in the rubber stopper; the nitrogen and evaporated gases exit through the other tube, pass through an empty Erlenmeyer flask, and finally bubble through a third Erlenmeyer flask containing a solution of sodium hydroxide $(\mathrm{NaOH})$ in order to neutralize the purge gases before they are vented through the hood. Figure 1 shows a schematic drawing of the process. If the evaporating gases from the Pd-aqua regia solution are vented directly to the hood, severe corrosion of the hood can occur. The empty flask is used to prevent siphoning of base solution into the Pd-aqua regia vessel.

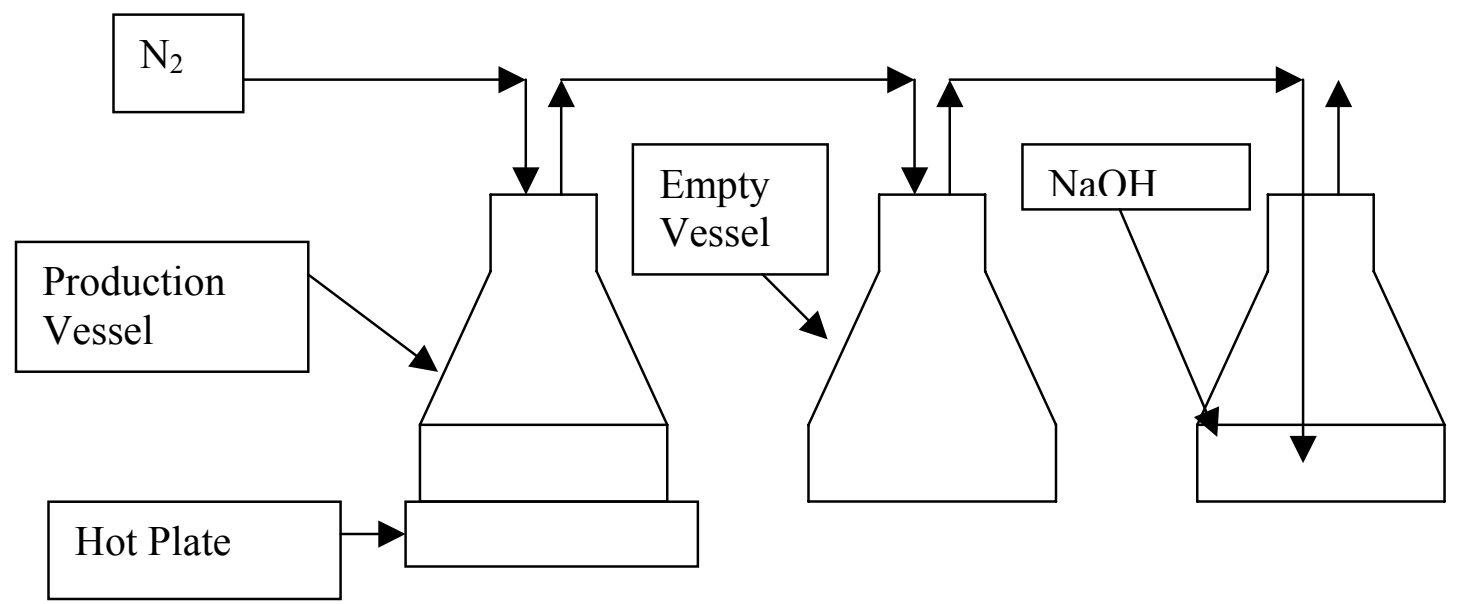

Figure 1: Schematic of Intermediate Production Setup

4. After the evaporation step above is complete, concentrated $\mathrm{HCl}$ is added to the Pd flask to dissolve the nearly dry $\mathrm{H}_{2} \mathrm{PdCl}_{4}$. Care is taken to ensure that any $\mathrm{H}_{2} \mathrm{PdCl}_{4}$ that has splashed onto the sides of the flask is dissolved. The solution is then boiled to near dryness, using the same neutralization setup shown in Figure 1. This step is repeated until the evaporated gases become colorless. Typically two additions of about $500 \mathrm{~mL}$ of $\mathrm{HCl}$ are used.

5. After the final $\mathrm{HCl}$ addition and evaporation step, when the $\mathrm{H}_{2} \mathrm{PdCl}_{4}$ becomes nearly dry, a concentrated aqueous solution containing $462 \mathrm{~g}$ of $\mathrm{NaCl}$ in about $2 \mathrm{~L}$ of DI water is added to the Pd flask to produce $\mathrm{Na}_{2} \mathrm{PdCl}_{4}$. The vessel is then boiled until dry, without treatment of the outlet gas.

6. Water (about $500 \mathrm{~mL}$ ) is added to dissolve the $\mathrm{Na}_{2} \mathrm{PdCl}_{4}$, and the solution is boiled to dryness. This step may be repeated, but typically is performed only once. 
7. Water (about $4 \mathrm{~L}$ ) is once again added to dissolve the $\mathrm{Na}_{2} \mathrm{PdCl}_{4}$. The resulting solution is continuously agitated using a Teflon-coated magnetic stir bar and heated on a hot plate to a temperature slightly above $90^{\circ} \mathrm{C}$, but lower than boiling.

8. Concentrated reagent grade $14.8 \mathrm{~N}$ ammonium hydroxide $\left(\mathrm{NH}_{4} \mathrm{OH}\right)$ is then added dropwise to the hot solution (stirring is continued during this process) to produce tetraamminedichloropalladium, $\mathrm{Pd}\left(\mathrm{NH}_{3}\right)_{4} \mathrm{Cl}_{2}$. Initially, there is formation of precipitate, $\mathrm{Pd}\left(\mathrm{NH}_{3}\right)_{2} \mathrm{Cl}_{2}$. As the solution becomes basic, the precipitate dissolves. Concentrated $\mathrm{NH}_{4} \mathrm{OH}$ is added dropwise until all of the $\mathrm{Pd}\left(\mathrm{NH}_{3}\right)_{2} \mathrm{Cl}_{2}$ dissolves, and the $\mathrm{pH}$ of the solution reaches a value of approximately 8 . The solution is then cooled and filtered to remove impurities.

9. The filtered solution is placed into an ice bath. A solution of $1200 \mathrm{~mL}$ of $6 \mathrm{M} \mathrm{HCl}$ is made and placed into a separate ice bath. When both solutions become cold (approximately $2^{\circ} \mathrm{C}$ ), the $\mathrm{HCl}$ is poured into the $\mathrm{Pd}\left(\mathrm{NH}_{3}\right)_{4} \mathrm{Cl}_{2}$ solution to precipitate $\mathrm{Pd}\left(\mathrm{NH}_{3}\right)_{2} \mathrm{Cl}_{2}$, which is then isolated by filtration and rinsed with cold $2 \mathrm{M} \mathrm{HCl}$.

10. The isolated precipitate is placed in a fume hood for several days to dry at room temperature and to evaporate any remaining $\mathrm{HCl}$ from the $\mathrm{Pd}\left(\mathrm{NH}_{3}\right)_{2} \mathrm{Cl}_{2}$.

11. The dry $\mathrm{Pd}\left(\mathrm{NH}_{3}\right)_{2} \mathrm{Cl}_{2}$ is subsequently ground into a fine powder using a mortar and pestle. This step makes the powder easier to dissolve in the Pd precipitation reaction.

During part of FY01, the intermediate preparation procedure used at ISU was modified by not doing the $\mathrm{NaCl}$ solution heating and evaporation step and not doing the DI water addition, heating, and evaporation step - in order to speed up production of the $\mathrm{Pd}\left(\mathrm{NH}_{3}\right)_{2} \mathrm{Cl}_{2}$ intermediate. The IR-photoacoustic spectra of samples of $\mathrm{Pd}\left(\mathrm{NH}_{3}\right)_{2} \mathrm{Cl}_{2}$ produced at $\mathrm{AL}$ using the normal procedure and this modified procedure showed no discernible differences.

In FY01, the intermediate preparation procedure used at AL was modified (from the procedure listed in Appendix 2 of the FY99 report) by decreasing the solution volumes used, where possible, and using a higher nitrogen gas purge flow rate - in order to speed up production of the $\mathrm{Pd}\left(\mathrm{NH}_{3}\right)_{2} \mathrm{Cl}_{2}$ intermediate. Generally, $\sim 185$ grams of Pd was dissolved in a mixture of $\sim 270 \mathrm{~mL}$ concentrated $\mathrm{HNO}_{3}$ and $\sim 500 \mathrm{~mL}$ concentrated $\mathrm{HCl}$ in a 4-L glass flask. This flask was capped using a polyethylene cup-type stopper that had two holes (nitrogen gas purge inlet and outlet); the outlet line was connected to a second 4-L flask that contained a solution of $\mathrm{NaOH}$ to partially neutralize the acid-gas vapor prior to being vented to the hood. Only two $(\sim 150 \mathrm{~mL}$ volume $)$ $\mathrm{HCl}$ addition, heating, and evaporation steps were performed, and only one ( $\sim 150 \mathrm{~mL}$ volume $)$ DI water addition, heating, and evaporation step was performed. The other steps in the procedure were not modified, but simply scaled according to the mass of Pd used in the procedure. 


\section{Appendix B. Notes on PD301-PD318 Precipitation Experiments}

\section{PD301}

Small 2-blade mixer paddle.

Initial $\mathrm{pH} 7.3$

0:00 Add reducing agent at $276 \mathrm{~mL} / \mathrm{min}$.

0:15 Solution begins to darken.

0:30 Solution becomes black.

1:00 Reducing agent addition stops.

1:45 Bubbling begins.

2:30 Bubbling continues, Bright Pd forms and clings to bottom.

9:30 Palladium metal on bottom of reactor. Solution above is clear.

Palladium gathers on the opposite side of the reactor with respect to mixer paddle.

30:00 Turn mixer off. Remove mixer paddle.

Final pH 8.67

PD302 Scale-up of PD225

Size 2, 2-blade mixer paddle used.

Initial $\mathrm{pH} 7.23$

0:00 Add reducing agent at $2220 \mathrm{~mL} / \mathrm{min}$

0:12 Stop addition. Solution is grey.

0:45 Bright Pd has formed near the top of the reactor. Bubbling begins.

1:00 Bubbling is rapid.

1:17 Bubbling is slowing.

1:21 Bubbling stops quickly.

2:00 Solution is dark and bright Pd has coated the reactor sides.

2:30 Bright Pd is peeling near the top of the reactor.

3:00 Bright Pd is peeling at all places on the reactor wall.

4:00 More Peeling. Some wobble noticed in impeller.

6:00 Almost all bright Pd peeled.

7:00 It appears as if Pd crystals are just moving in clear solution. No changes are obvious.

30:00 Turn mixer off. Remove mixer paddle.

Final $\mathrm{pH} 8.3$

\section{PD303}

When dissolving the DADCIPd the top of the solution has pink bubbles and some pink precipitate.

Heated solution to a boil and then cooled to reaction temperature again. Pink color is gone.

Size 2, 2-blade mixer paddle used.

0:00 Add reducing agent at $3330 \mathrm{~mL} / \mathrm{min}$.

0:03 Solution begins to darken.

0:06 Solution is black.

0:08 Stop addition.

1:00 There is a lot of bubbling.

1:42 Bright Pd coats the sides of the reactor. It is beginning to be pulled off of the reactor. Near the bottom, the remaining bright Pd looks wiry or "stringy"

2:00 Top 1/3rd part of reactor is free of Pd crystals. (No crystals are moved into that space by the mixer.)

3:30 Crystals pile up on opposite side of reactor with respect to the mixer paddle.

4:30 Solution is very clear. 
5:00 Small square of bright Pd is stuck to back wall of reactor near the top of the reactor. (Front refers to the location of the mixer paddle.)

6:30 Square of bright Pd is beginning to pull away from the reactor wall.

8:00 Square is stretched out and waving like a flag.

Dead zone still present. Wiry Pd is still intact on front of reactor.

30:00 Turn mixer off. Remove mixer paddle.

Final $\mathrm{pH} 8.49$

\section{PD304}

4-blade mixer paddle used.

Initial $\mathrm{pH} 7.5$

0:00 Add reducing agent $2220 \mathrm{~mL} / \mathrm{min}$.

0:05 Solution begins to darken.

$0: 22 \quad$ Solution is black.

0:30 pH after RA 5.34

2:30 No evidence of bright Pd. Very little bubbling.

2:50 Small amount of bubbling.

3:00 Bright Pd definitely present and totally coats reactor sides.

Solution has cleared and Pd has settled.

4:00 Bright Pd reflects a lot. Hard to see inside reactor well.

5:30 MIXER STOPS. HIGH TORQUE.

6:30 Mixer restarted.

6:45 Bright Pd being pulled from wall. Stringy remains.

9:00 Solution much clearer. Particles clearly visible. Very little bright Pd on wall.

10:00 MIXER STOPS. HIGH TORQUE.

12:30 Restart (80 rpm). Mixer heavily coated with bright Pd. Reactor floating around too much. Even at $80 \mathrm{rpm}$ this mixer paddle (4 pitched blade impeller) creates a much better suspension than the 2-blade impeller.

30:00 Turn mixer off. Remove mixer paddle.

Final pH 8.26

$* * *$ Further experiments will be done with a secured reactor. $* * *$

\section{PD305}

4-Blade Impeller. Centered.

0:00 Add reducing agent $3330 \mathrm{~mL} / \mathrm{min}$.

0:08 Stop addition of reducing agent.

$0: 16 \quad$ Solution becomes dark.

2:55 Bubbling.

3:20 Bright Pd coats reactor walls.

4:20 Bright Pd loosening. (Starting to break from reactor wall.)

5:45 Bright Pd breaking away from wall.

6:26 Solution grey with Pd solids visible.

9:00 More bright Pd coming off of wall.

11:11 Mixer paddle heavily coated in Palladium.

13:13 Solution very clear.

13:39 Pd seems to gather at large radial positions.

14:40 Not as much peeling as usual

16:54 Less vortexing after reaction than before.

22:45 Crystals seem to propagate more to lower half

* things become more visible when solution clears. 
25:00 Most bright Pd is still attached to the reactor wall.

30:00 Stop Mixer.

\section{PD306}

4-Blade Impeller. Off Center.

Initial $\mathrm{pH} 7.36$

0:00 Add reducing agent $3330 \mathrm{~mL} / \mathrm{min}$.

0:06 Darkening Begins.

0:08 Stop addition.

$0: 22 \quad$ Solution is brown.

0:30 pH after RA 5.30

1:00 Solution is black.

4:15 Bubbling begins.

4:30 Walls of reactor coated in bright Pd.

5:30 Solution grey.

6:00 Bright Pd is peeling.

7:00 More peeling on top half of reactor.

10:13 Solution is quite clear.

13:00 Top half of reactor almost completely clear. Bottom half is mostly covered.

15:16 Solution is totally clear.

15:45 Mixer appears to be heavily covered in Pd.

26:50 Small vortex is visible.

30:00 Stop Mixer.

Final $\mathrm{pH} 8.44$

*** Impeller blades are not as heavily covered as previously suspected. $* * *$

\section{PD307}

4-Blade Impeller. Off Center.

Initial $\mathrm{pH} 7.13$

0:00 Add reducing agent $3330 \mathrm{~mL} / \mathrm{min}$.

0:01 Solution begins to darken.

0:08.5 Stop addition.

$0: 10 \quad$ Solution is dark with greenish color.

$0: 30 \quad$ Solution is dark.

2:00 Slight bubbling is observed.

2:42 Faster bubbling.

3:00 Reactor coated in bright Pd.

3:30 Bubbling is slowing.

3:45 Bubbling almost stopped.

3:58 Grey solution.

4:11 Bright pulling away from wall.

4:28 Solution clearer.

4:40 Bubbling gone.

5:30 Peeling more toward middle of reactor.

5:48 Solution looks pretty clear.

6:20 Pd crystals visible from above reactor. (Still cannot see through bright coating well.) **Some of the bubbling may not have been due to chemical reaction.

9:30 Enough Palladium has peeled to see into reactor from the side.

12:08 Solution is quite clear.

30:00 Stop mixer. 
Final pH 8.13

\section{PD308}

4-Blade Impeller. Off Center. Reactor Coated in Pd to start. Initial $\mathrm{pH} 7.05$

0:00 Add reducing agent $3330 \mathrm{~mL} / \mathrm{min}$.

0:08 Solution a brownish green.

0:45 Solution black.

2:41 Bubbling starts.

3:00 Coating less shiny than previous experiments.

3:20 Coating is shiny.

3:45 Bubbling stops.

4:00 Grey "solution"

4:24 Coating breaking off slightly.

6:00 No more noticeable breakup.

6:53 Nothing is visible through reactor walls (coating too shiny).

7:12 Solids are visible from above (solution has cleared up).

10:03 Bright Pd breaking off of wall again.

13:13 Solution becomes clear. Crystals are easy to see.

23:05 Gradually, more Pd breaking from walls.

30:00 Stop Mixer.

Final pH 8.19.

\section{PD309}

2-Blade Impeller. Size 2. Off Center.

Initial pH 6.94.

0:00 Add reducing agent $3330 \mathrm{~mL} / \mathrm{min}$.

0:06 Darkening Begins.

0:08 Stop addition.

0:30 pH after RA 5.28

$0: 40 \quad$ Solution is dark.

2:25 Very Slow Bubbling.

3:23 Bubbling speeds up.

3:45 Fast Bubbling.

4:10 Bubbling Stops.

5:38 $\sim 5$ Small bright pd flakes floating.

7:12 Solution Clearing.

7:35 Precipitate becoming visible

11:08 Solution is pretty clear.

12:38 Solution is quite clear.

18:00 Reactor not peeling as usual.

24:00 No change observed.

30:00 Stop mixing.

Final $\mathrm{pH} 8.29$

\section{PD310}

2-Blade Impeller. Size 2. Off Center.

** Reducing agent dumped in all at once $(\sim 1 \mathrm{sec})$

Initial $\mathrm{pH} 7.03$

0:00 Add reducing agent $(444 \mathrm{~mL})$ 
0:09 Bubbling Observed

0:30 Greenish solution. pH after RA 3.51.

1:16 Beaker coated with bright Pd

1:33 Rapid Bubbling.

1:41 Beaker completely coated

2:10 Bubbling dying.

2:25 Bubbling stopped.

2:45 Grey color.

4:23 Solution darkening.

5:51 Solution lightening; solid Pd visible.

9:00 Solution quite clear.

11:46 Bright Pd beginning to peel.

15:35 Not much peeling. Beaker can only be observed from above.

30:00 Stop Mixer.

* Bright Pd comes off of beaker very easily when rinse water was added.

Final pH 7.55.

\section{PD311}

**PD311 is a repeat of PD231. All reaction conditions were identical. However, the mid sized mixer paddle was used (in PD231 a smaller mixer paddle was used).

Initial $\mathrm{pH} 7.3$

$0-9 \mathrm{sec}$ Addition of reducing agent.

2:00 Bubbling is noticed.

2:24 Faster Bubbling was observed.

2:30 The walls of the reactor were coated with bright palladium.

2:55 Rapid Bubbling was observed.

3:10 The bubbling stopped.

9:00 The solution is clearing.

10:30 The solution is now clear; solid Pd is visible.

13:40 It appears as if more Pd is on walls than is usual.

Final $\mathrm{pH} 8.4$

\section{PD312}

**PD312 is a repeat of PD247. All reaction and mixing conditions were reproduced. Initial pH 7.3

$0-8 \mathrm{sec}$ Addition of reducing agent.

40sec Bubbling is observed. The reactor is coated with palladium.

1:25 The bubbling stopped.

2:45 Solids are visible.

4:15 Bright Pd is peeling from the reactor walls.

9:30 The particles look well distributed throughout the reactor.

14:00 Almost complete peeling has occurred near the middle of the reactor.

29:30 The vessel wall is almost clear of all bright Pd due to peeling.

Final $\mathrm{pH} 8.3$

\section{PD313}

Initial $\mathrm{pH} 7.3$

0-11s Addition of reducing agent. (This was slower than in PD312.)

1:00 The reactor is coated with bright $\mathrm{Pd}$.

1:30 Fast bubbling. 
1:55 Very Fast bubbling.

2:00 The bubbling died. Solution is grey color.

4:00 Solids were visible. The solution was clearing.

6:30 Peeling began at point on wall nearest to the impeller.

6:45 Suspension appeared to be not as good as in the previous reaction.

10:02 Suspension appeared to be better than observed at 6:45.

19:30 Further peeling occurred.

21:30 Most of the reactor is still covered with bright $\mathrm{Pd}$.

Final $\mathrm{pH} 8.4$

\section{PD314}

**PD314 is a replication of PD311. All reaction conditions were identical.

$0-9 \mathrm{sec}$ Addition of reducing agent.

0-21s Darkening of solution.

2:14 Bubbling starts and reactor is coated.

2:35 Rapid Bubbling.

2:55 End Bubbling.

3:40 Solution is a milky grey color.

7:21 Solution clearing. Solids slightly visible.

9:00 Solution fully clear

18:10 Peeling just beginning. A lot of PD black is stuck to walls of reactor.

25:00 Still, very little peeling has occurred.

Final $\mathrm{pH} 8.3$

\section{PD315}

**PD315 is a scale down of PD313. (Addition over 12 seconds, NOT 9!)

2-blade mixer paddle, size 1 used.

Initial $\mathrm{pH} 7.3$

$0-12 \mathrm{~s}$ Addition of reducing agent.

30sec Darkening

1:10 Start bubbling.

1:45 End bubbling.

1:55 Reactor coated.

2:00 Peeling begins.

3:20 Solids visible.

3:50 More peeling.

4:50 Clump of powder at bottom of reactor.

12:00 More Peeling.

20:00 Bottom half of reactor almost completely clear of Pd.

25:00 More peeling in top section.

30:00 Stop.

Final $\mathrm{pH} 8.4$

\section{PD316}

**PD316 is a repeat of PD313, but $8 \mathrm{sec}$ addition is the goal. (Addition took place over 10 seconds.) 2-blade mixer paddle, size 2 was used.

Initial $\mathrm{pH} 7.3$

$0-10 \mathrm{~s}$ Addition of reducing agent

30sec pH 5.34.

1:00 Bubbling starts. 
1:48 Bubbling ends.

5:00 Solution Clearing

5:39 Bad macromixing is visible. Solids are mostly at bottom of reactor. Those that move are only those near the impeller.

30:00 Stop

Final pH 8.42.

\section{PD317}

**PD317 is a constant power per unit volume scale-up of PD416 (mixer not centered).

2-blade mixer paddle, size 2 was used. off center mixing.

Initial $\mathrm{pH} 7.2$

$0-8 \mathrm{sec}$ Addition of reducing agent.

$38 \mathrm{sec}$ Bubbling starts

1:10 Second bubbling. Bubbles over beaker walls!!

1:30 Turn Mixer speed down

7:45 Solution is clearing.

11:00 Solution is clear. Stirring was not moving the particles much especially away from the impeller.

26:00 Bright Pd is peeling away from walls.

30:00 Stop mixer.

Final $\mathrm{pH} 8.62$

\section{PD318}

**PD318 is a constant power per unit volume scale-up of PD416

2-blade mixer paddle, size 2 was used. Centered mixing.

Initial $\mathrm{pH} 7.15$

0-9sec Addition of reducing agent.

$45 \mathrm{sec}$ Bubbling starts

1:03 Bubbles die

1:14 Second bubbling

1:30 Walls coated with bright Pd.

1:30 Turn down mixer speed.

6:00 Solution starting to clear up

$7: 15 \quad$ Solution clearer.

7:30 Very few particles are suspended.

8:18 Solution is completely clear.

9:15 Nothing significantly off the bottom of reactor. (No particles are suspended very far above the impeller blades.)

30:00 Stop mixer.

Final pH 8.43 


\section{Appendix C. ISU Procedure for Reductive Precipitation of Palladium (Pfaudler Reactor)}

Palladium metal powder is precipitated by dissolving $\mathrm{Pd}\left(\mathrm{NH}_{3}\right)_{2} \mathrm{Cl}_{2}$ in a mixture of water with ammonium hydroxide $\left(\mathrm{NH}_{4} \mathrm{OH}\right)$ and adding a reducing agent consisting of a mixture of formic acid and sodium formate. The following procedure is used to precipitate Pd metal using the 20gallon Pfaudler reactor. Small deviations from this procedure are described in the discussion of the experimental results.

1. 50 Liters of deionized (DI) water is added to the Pfaudler reactor. Another 8.4 Liters of water is measured out and held in reserve for use in other steps described below.

2. The reactor impeller is rotated at $100 \mathrm{rpm}$.

3. The valve is opened to allow steam to enter the reactor steam jacket. The setpoint temperature on the temperature controller is adjusted to bring the reactor contents to $60^{\circ} \mathrm{C}$.

4. The palladium intermediate $\mathrm{Pd}\left(\mathrm{NH}_{3}\right)_{2} \mathrm{Cl}_{2}$ is weighed out (1246.9 g), into one or two beakers.

5. The vent gate to the reactor snorkel hood is closed to prevent loss of Pd intermediate powder during subsequent addition to the reactor.

6. The weighed Pd intermediate is added to the reactor using a scoop, placing it through the reactor hand-hole.

7. The beaker(s) that contained the Pd intermediate is rinsed with a small amount of the remaining water (step 1) to clean the beaker and remove any remaining intermediate. This rinse is added to the reactor through the hand-hole.

8. The DI water-Pd intermediate solution is stirred for a short period of time prior to adding the $\mathrm{NH}_{4} \mathrm{OH}$ (step 9), so that most of the intermediate settles down into solution.

9. The vent gate to the reactor snorkel hood is opened. Concentrated reagent grade $14.8 \mathrm{~N}$ $\mathrm{NH}_{4} \mathrm{OH}(727 \mathrm{~mL})$ is pumped into the reactor using a peristaltic pump. The remaining reserve water (step 1) is immediately pumped behind the $\mathrm{NH}_{4} \mathrm{OH}$ to ensure that all of it is delivered to the reactor and that none is left in the pump tubing.

10. The mixture in the reactor is then allowed to heat to $60^{\circ} \mathrm{C}$ and to stir until all of the $\mathrm{Pd}\left(\mathrm{NH}_{3}\right)_{2} \mathrm{Cl}_{2}$ dissolves (approximately 4 hours).

11. While step 10 is underway, the reducing agent is prepared. The desired quantities of sodium formate, formic acid, and water are placed into a 5-L glass jar. However, because a tubing pump is later used to introduce the reducing agent to the reactor, a quantity of reducing agent greater than that which is to be introduced into the reactor is prepared.

12. The mixture is then placed on a hot plate and heated and stirred using a Teflon-coated magnetic stir bar until all of the sodium formate dissolves and the solution reaches the desired temperature, $60^{\circ} \mathrm{C}$.

13. The $\mathrm{pH}$ of solution in the reactor is measured. Small amounts (a few $\mathrm{mL}$ at a time) of concentrated hydrochloric acid $(\mathrm{HCl})$ are added to the reactor in order to adjust the $\mathrm{pH}$ to a value between 7.2-7.3. If too much $\mathrm{HCl}$ is added, a small amount of $\mathrm{NH}_{4} \mathrm{OH}$ is added to bring the $\mathrm{pH}$ back to the range 7.2-7.3.

14. The impeller speed is adjusted to the desired value to be used during the reducing agent addition step.

15. The hot plate supporting the vessel containing the reducing agent is turned off and the tubing pump intake tube is placed into the reducing agent solution. The outflow tube from the pump is placed into the glass feed tube on the reactor. The tubing pump (previously calibrated flow rate) is then started, and the appropriate amount of reducing agent solution is pumped 
into the reactor by timing how long the pump is activated (including the time required to fill the pump tubing dead volume). This timing method delivers desired volumes within an accuracy of a few percent. For experiments PD501-509, the amounts of sodium formate, formic acid, and water pumped into the reactor were approximately $1196 \mathrm{~g}, 256.4 \mathrm{~mL}$, and $2.75 \mathrm{~L}$, respectively.

16. The pump tube is removed from the reactor feed tube after addition of the reducing agent solution. The feed tube is then rinsed with a small amount of water $(15-20 \mathrm{~mL})$ and removed from the reactor.

17. The reaction is allowed to proceed for 30 minutes after adding the reducing agent. In some cases, the impeller speed is changed early (after approximately 3 minutes) during this 30 minute interval.

18. The impeller is stopped at the end of the 30-minute reaction time, and the $\mathrm{pH}$ of the solution in the reactor is measured.

19. A plug in the exit pipe at the bottom of the reactor (used to displace the poorly-mixed exit pipe volume) is removed from the reactor.

20. The steam supply to the reactor is turned off, and the contents of the reactor are allowed to cool for several hours.

21. A strainer fitted with a large filter bag (150-mesh) is then connected to the reactor.

22 . The reactor impeller is activated at a low rotation rate $(130 \mathrm{rpm})$.

23. The reactor exit valve is opened, allowing the Pd powder and reaction solution to flow to the strainer.

24. A diaphragm-tubing pump is used to pump reaction solution from the strainer into a 55gallon storage drum for later disposal.

25. The walls of the strainer are rinsed to collect any Pd that may have stuck to the walls. The filter bag containing the solids is then removed from the strainer.

26. The Pd in the filter bag is washed with deionized water several times and then soaked in deionized water for several hours.

27. The Pd is removed from the filter bag and placed into a $4 \mathrm{~L}$ beaker. Water is added and the mixture is heated on a hot plate until it reaches $60^{\circ} \mathrm{C}$.

28. The liquid in the beaker is decanted. Water is then added to the beaker and subsequently decanted without heating several (10 or more) times.

29. The isolated $\mathrm{Pd}$ is placed on large watch glasses and heated in an oven at $90-110^{\circ} \mathrm{C}$ for a minimum of 24 hours.

30. The dried Pd is placed in a sieve pan stack containing 20-mesh, 60-mesh, and 100-mesh sieve pans. It is sieved for several hours until nearly all of the Pd metal passes through all three screens.

31. The sieved powder is collected, weighed, coned, and quartered.

Deviations from the above procedure:

1. For Pd501 the vent to the snorkel hood was not closed prior to the addition of the $\mathrm{Pd}$ intermediate powder.

2. For Pd507 and Pd508 the reducing agent was manually poured into the reactor (through a funnel placed on top of the glass feed tube) instead of being pumped.

3. For PD508 the reducing agent was heated particularly slowly before being added to the reactor. 
4. For Pd509 the reducing agent was heated in a water-recirculating bath, and the intermediate was fully dissolved in a mixture of water and $\mathrm{NH}_{4} \mathrm{OH}$ before being added to the reactor. No $\mathrm{NH}_{4} \mathrm{OH}$ was added directly to the reactor. The reaction was also run with the hand-hole open.

5. For two batches, PD501 and 507, a 40-minute reaction time was used rather than the normal 30-minute reaction time.

6. Not all of the PD501-509 batches were allowed to cool for several hours prior to filtration; some were filtered almost immediately (within a few minutes) after the reaction was completed.

7. The Pd-DI water rinse procedure that is listed (steps 26-28) was developed over the course of doing PD501-509; slightly less effective DI water rinsing procedures were used for some of the initial batches done using the Pfaudler reactor. 


\section{Appendix D. Notes on Pfaudler Reactor PD501-PD509 Precipitation Experiments}

PD501 Constant power/volume scale-up of PD422

Initial $\mathrm{pH} 7.24$

$0-11.5 \mathrm{sec} \quad$ Addition of reducing agent.

$27 \mathrm{sec}$ Solution turns opaque.

$1: 42$ Bubbling begins.

2:33 Bubbling ends.

$2: 45$ Solution is grey.

9:00 Solution begins to clear.

21:15 Impeller blades are visible (darker and light oscillating colors).

25:00 Blue is visible on impeller blades.

29:12 Solution is much clearer.

30:00 Plug at bottom of reactor is visible.

Bright Pd visible - moving in suspension.

40:00 Stop.

Final $\mathrm{pH} \sim 8$. (There was a problem with the $\mathrm{pH}$ probe. $\mathrm{pH}$ paper was used.)

PD502 Repeat of PD501 with higher mixer speed (2nd mixing time) 12-11-00

Solution $\mathrm{pH} 8.02$ adjusted with $36 \mathrm{~mL}$ conc. $\mathrm{HCl}$ to $\mathrm{pH} 7.2$

$10 \mathrm{sec}$ Brown solution

$20 \mathrm{sec}$ Dark solution

1:36 Bubbling begins

1:58 Bubbling faster

2:39 Bubbling ends

3:00 Mixer speed increased from $130 \mathrm{RPM}(27.4 \mathrm{~Hz})$ to $190 \mathrm{RPM}(40 \mathrm{~Hz})$.

6:00 Solution is still dark.

8:50 Clearer Solution

10:30 Residual Bubbling

10:47 Impeller Blades Observed

13:40 Solid Pd chunks obvious.

18:00 Temp on controller $=66.6$

There is too much Pd in suspension to see the bottom of the reactor well.

26:00 Temp on controller $=65.8$

30:00 Temp on controller $=65.7$; Mixer turned off

Mixer blades free from palladium. Palladium on bottom of reactor

Final $\mathrm{pH}=8.04$

PD503 Repeat of PD502 with higher mixing speed.

$\mathrm{pH}$ before adjust $=8.6$

adjust with $129 \mathrm{~mL} \mathrm{HCl}$ then $21 \mathrm{~mL} \mathrm{NH} 4 \mathrm{OH}$

**New $\mathrm{pH}$ probe acting strange?? Initial $\mathrm{pH} \sim 7.3$

$0 \mathrm{sec}$ Start pump.

$10 \mathrm{sec}$ Solution is darkening.

$16 \mathrm{sec}$ Stop pump. Solution is dark grey.

50 sec Murky grey solution.

2:07 Bubbling Starts.

3:00 Adjust mixer speed to 262.2 RPM $(55 \mathrm{~Hz})$.

$<3: 30$ Bubbling stops. At this point it is hard to see much inside the reactor. The fluid is moving quite fast. 
4:56 $\mathrm{T}=61.8$ (Controller reads 68.8)

8:22 Solution appeared to be clearing.

11:30 Solution is definitely clearer.

30:00 Stop mixer.

Final $\mathrm{pH} \sim 8.6$

**Bottom plug became dislodged during reaction.

\section{PD 504}

Repeat of PD502. Mixing speed held at 262.2 RPM (55 Hz) over entire reaction. Also, the addition tube was removed from solution immediately after addition of the reducing agent. Further, different tubing was used to add reducing agent to the reactor. The reducing agent is added over $11 \mathrm{sec}$, but the tubing now takes less time to fill, so the pump was stopped at $14 \mathrm{sec}$.

$\mathrm{pH}$ before adjust $=7.92$; adjust with $33 \mathrm{~mL}$ of $\mathrm{HCl}$

Initial $\mathrm{pH}=7.25$

$0 \mathrm{sec}$ Start pump. It was pretty hard to see very much inside of the reactor. The impeller was turning too fast. Temp $=60 \mathrm{C}$.

$\sim 10 \mathrm{sec}$ The solution is darkening.

$14 \mathrm{sec}$ Stop pump. Remove addition tube from reactor.

$15 \mathrm{sec}$ Solution is dark.

1:30 Bubbling begins.

2:00 Temp $=60.7 \mathrm{C}$

2:06 Bubbling stops.

2:30 Solution is a milky grey color.

3:00 Temp $=61.5 \mathrm{C}$

4:00 Temp $=61.5 \mathrm{C}$

5:00 Temp $=61.4 \mathrm{C}$

14:16 Solution appears to have become much more clear in a very short amount of time.

The plug at the bottom of the reactor is now visible.

18:46 Temp $=60.0$

30:00 Stop Mixer.

Final $\mathrm{pH}=8.36$

PD505

Repeat of PD504. Mixer speed held at 130 RPM $(27.4 \mathrm{~Hz})$ for entire reaction. Also, reducing agent solution was pumped in over 12 seconds at the same rate as it had been pumped in the past. As a result, a larger volume of reducing agent was used.

pH before adjust 7.73; adjust with $27 \mathrm{~mL} \mathrm{HCl}$

Initial $\mathrm{pH} 7.27$

$0 \mathrm{sec}$ Start pump.

$0-9 \mathrm{sec}$ Solution darkened.

$15 \mathrm{sec}$ Stop pump.

$16 \mathrm{sec}$ Grey solution.

1:43 Bubbling begins.

2:12 Bubbling is faster.

2:26 Fastest bubbling.

2:35 Bubbling slows.

2:57 Bubbling ends.

3:44 Murky Grey color. 
5:09 Temp $=61.4 \mathrm{C}$

9:00 Temp $=61.3 \mathrm{C}$

10:00 Temp $=61.1 \mathrm{C}$

12:18 The impeller blades became visible.

16:10 The reactor lightened quickly. The plug was at the bottom of the reactor visible.

$16: 44$ Temp $=60.5 \mathrm{C}$

22:00 Temp $=59.6 \mathrm{C}$

30:00 Stop reaction. Temp $=59.3 \mathrm{C}$

Final $\mathrm{pH}=8.4$

* A large $(2.6 \mathrm{~cm} * 1.6 \mathrm{~cm} * 0.7 \mathrm{~cm})$ chunk of palladium came out of the reactor. It did not break into smaller pieces easily, and is still in tact.

\section{PD506}

Repeat of PD505, but a longer addition time for the reducing agent was used ( $20 \mathrm{sec})$.

Mixer Speed $27.4 \mathrm{~Hz}=130 \mathrm{RPM}$

$\mathrm{pH}$ before adjust 7.56; add $12.5 \mathrm{~mL} \mathrm{HCl}$

$\mathrm{pH}$ after adjust 7.26

$0 \mathrm{sec}$ Pump was started.

$3.8 \mathrm{sec}$ Solution began to flow into reactor

23.8s Pump was stopped.

$50 \mathrm{sec}$ Solution was dark

1:39 Bubbling began.

2:08 Heavy bubbling was occurring.

2:24 Bubbling ended.

3:00 Temp $=61.6 \mathrm{C}($ display $=68.6)$

4:00 Temp $=61.8 \mathrm{C}($ display $=68.8)$

5:00 Temp $=61.8 \mathrm{C}($ display $=68.8)$

7:00 Temp $=61.6 \mathrm{C}($ display $=68.6)$

9:00 Temp $=61.4 \mathrm{C}($ display $=68.4)$

15:08 Solution looked lighter.

30:00 Mixer was stopped.

Final pH 8.34

*The temperature momentarily rose to $61.9 \mathrm{C}$ between the 4:00 and 5:00 on the stopwatch.

**This experiment was run when it was still light outside. In the past it had been later in the evening when experiments were run. It was much harder to see a lot of detail in the reactor because of the glare.

\section{PD507}

Repeat of PD506 with shorter addition time $(8 \mathrm{sec})$ and slower mixer speed (70 RPM). Also, the reactor ran for $40 \mathrm{~min}$ instead of $30 \mathrm{~min}$ because it appeared as if changes in solution color had happened more slowly.

$\mathrm{pH}$ before adjust 8.0; adjust with $32 \mathrm{~mL} \mathrm{HCl}$

Initial $\mathrm{pH}=7.3$

$0-8 \mathrm{sec}$ Addition of reducing agent by pouring from a $4 \mathrm{~L}$ beaker into a funnel then through addition tube.

0:57 Slow bubbling had started.

2:00 Temperature $=60.5 \mathrm{C} \quad($ display $=67.5)$

2:30 Bubbling appeared to be continuing. However, it looked as if there might have been something other than bubbles floating on the top of the fluid. 
3:00 Bubbling had stopped. There appeared to be something else, more like a film, on the surface of the fluid. It was not a continuous film. It appeared to be a small number of "islands" instead.

4:00 Temperature $=60.9 \mathrm{C} \quad($ display $=67.9)$

4:55 Bubbles reappeared briefly.

5:00 Temperature $=61.3 \mathrm{C} \quad($ display $=68.3)$

5:30 Temperature $=61.6 \mathrm{C} \quad($ display $=68.6)$

6:00 Temperature $=61.8 \mathrm{C} \quad($ display $=68.8)$

Solution is murky.

7:00 Temperature $=62.1 \mathrm{C} \quad($ display $=69.1)$

8:00 Temperature $=62.2 \mathrm{C} \quad($ display $=69.2)$

9:00 Temperature $=62.3 \mathrm{C} \quad($ display $=69.3)$

13:30 Temp $=62.3 \mathrm{C} \quad($ display $=69.3)$

No obvious change in solution

15:00 Temp $=62.2 \mathrm{C} \quad($ display $=69.2)$

17:00 Temp $=62.2 \mathrm{C} \quad($ display $=69.2)$

Mixer blades were visible as flashes of dark and light. The blue color was not apparent.

20:00 Temp $=62.1 \mathrm{C} \quad($ display $=69.1)$

22:00 Temp $=61.9 \mathrm{C} \quad($ display $=68.9)$

25:30 Temp $=61.7 \quad$ (display $=68.7$ )

The solution appeared to be clearing up quickly.

27:45 Solution was pretty clear.

28.30 For a moment it appeared as if the plug was visible at the bottom of the reactor. It was hard to be certain.

30:00 Temp $=61.3 \mathrm{C} \quad($ display $=68.3$ )

Continued mixing.

$>31: 00$ The plug became visible.

33:30 Suspended chunks of Pd were visible.

35:00 Temp $=61.0 \mathrm{C} \quad($ display $=68.0)$

40:00 Temp $=60.7 \mathrm{C} \quad($ display $=67.7)$

Mixer was stopped.

Final $\mathrm{pH}=8.5$

* After the reaction the Pd was in sheets in the reactor. A large mass remained during the filtration process. The elbow and pipes were clogged with palladium.

* The product (before sieving) appeared to be less sized and shaped like large peas and more spongy than previous batches. (I don't know if spongy is the best word).

\section{PD508}

Repeat of PD507. With mixer speed 262 RPM (55 Hz), and time 30 min.

$\underline{\text { Reaction }}$

pH before adjust 7.78; adjust with $23.5 \mathrm{~mL} \mathrm{HCl}$

$\mathrm{pH}$ after adjust 7.25

Reducing Agent $\mathrm{pH} 4.47$

$0-8 \mathrm{sec}$ Addition of reducing agent by pouring from a $4 \mathrm{~L}$ glass beaker into a funnel. The funnel was inserted into the glass feed tube.

1:45 Bubbles were visible.

30min Stop Mixer.

Rinsing

Powder does not drain easily. 
Sieving (6 watchglasses total palladium)

Add two watchglasses to 20 -mesh sieve tray. Sieve for 30 min on lowest setting.

30 min: Rough Visual Estimates:

20-mesh pan: virtually empty

60-mesh pan: $\quad 20 \%$ of total powder

100-mesh pan: $\sim 35 \%$ of total powder

Bottom Pan: $\quad \sim 45 \%$ of total powder

* Bottom Pan: $112.8 \mathrm{~g}$

Sieved Powder was removed from bottom pan.

2 more watchglasses added to 20-mesh tray.

Sieving on lowest setting for $30 \mathrm{~min}$.

1:00:00

20-mesh pan: virtually empty

60-mesh pan: brights and some dark

100-mesh pan: mostly dark Pd

Total sieved Pd: $303.5 \mathrm{~g}$

The remaining two watchglasses were added to the 20-mesh tray

The powder was sieved for $30 \mathrm{~min}$ on the lowest setting.

1:30:00 Total sieved Pd: $504.5 \mathrm{~g}$

The sieve tray was run for $90 \mathrm{~min}$ on the lowest setting.

2:00:00 Total sieved Pd: $549.0 \mathrm{~g}$

2:30:00 Total sieved Pd: $556.3 \mathrm{~g}$

3:00:00 Total sieved Pd: $560.0 \mathrm{~g}$

PD509

6-26-01

This experiment was supposed to be experiment number 1 in a factorial design. There was an issue with the pumping of the reducing agent. After the pump was turned on, it took about 8 seconds before any fluid was introduced to the reactor. Typically, this time gap is about 3 seconds. During the next 6 seconds, the flow was very slow. Finally, the tubing was adjusted and fluid began to flow at full rate.

Mixing: $262 \mathrm{RPM} \quad(55 \mathrm{~Hz})$ for entire $30 \mathrm{~min}$.

Reaction:

$\mathrm{pH}$ before adjust: 7.7; Adjust with $17 \mathrm{~mL} \mathrm{HCl}$

$\mathrm{pH}$ after adjust 7.23

$0-\sim 8 \mathrm{sec} \quad$ No flow

$\sim 8-\sim 14 \mathrm{sec} \quad$ Slow Flow

$14-29 \mathrm{sec} \quad$ Full Flow.

* These times are rough estimates. The pump was stopped when it was approximated that the amount of reducing agent added was correct. This estimate was made based on visual estimates of the relative amount of reducing agent remaining in the vessel which contained it when compared with previous experiments.

$45 \mathrm{sec}$ The solution is a yellowish grey color with some bubbles around the impeller

2:33 The solution is bubbling over the entire surface.

2:51 Rapid bubbling is observed. The bubbles were pretty high in the reactor.

3:06 The bubbling has ended.

3:22 The solution had become a pale grey color.

4:15 The sight glass was open during this experiment. It could be the case that the bubbles were not as high in the reactor as previously thought. It is possible to see much closer to the wall with the 
sight glass open. The fluid level is much higher near the wall than at the center of the reactor. It is likely that normal bubbling was observed, but it was seen on fluid that is closer to the wall and higher in the reactor as well.

5:11 The solution had become clearer. Palladium solids are visible.

15:00 Occasional bubbling was observed. This could be due to decomposition of formate.

20:00 No change had been observed.

30:00 Stop motor.

\section{Sieving Notes}

Of 6 total watchglasses, the contents of two were added the 20 -mesh pan every 30 minutes. Initial Addition of Palladium: $204.9 \mathrm{~g}$

30 min sieving: $\quad 191.1 \mathrm{~g}$ sieved (Removed from bottom pan)

Add Unsieved Palladium: $\quad 167.3 \mathrm{~g}$

$1 \mathrm{hr}$ sieving ( 30 additional min) $355.4 \mathrm{~g}$ sieved (164.9 $\mathrm{g}$ Removed from bottom pan)

Add Unsieved Palladium: $\quad 183.6 \mathrm{~g}$

$1.5 \mathrm{hr}$ total sieving: $\quad 534.8 \mathrm{~g}$ sieved $(179.4 \mathrm{~g}$ Removed from bottom pan)

* The sieve shaker became very loud. I am currently investigating the cause of this noise. 
Appendix E. FY99 Palladium Processing Report

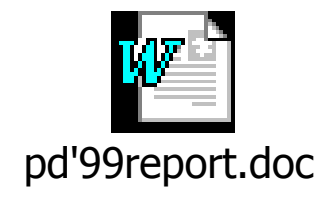

Appendix F. FY00 Palladium Processing Report

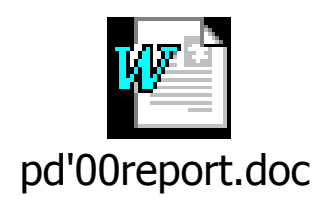

